\title{
$C_{0} \mathbf{I} \cdot \mathbf{R}^{\circ} \mathbf{P} \cdot \mathbf{E}^{\prime} \mathrm{E}$
}

Centre Interuniversitaire sur le Risque, les Politiques Économiques et l'Emploi

Cahier de recherche/Working Paper 10-19

\section{Equity Premia and State-Dependent Risks}

\author{
Mohammed Bouaddi \\ Denis Larocque \\ Michel Normandin
}

Mai/May 2010

Bouaddi : Department of Economics and CIRPÉE, HEC Montréal, 3000 Chemin de la Côte-Ste-Catherine, Montréal, Québec, Canada H3T 2A7. Tel. : 514 340-6451 ; Fax : 514 340-6469

mohammed.bouaddi@hec.ca

Larocque : Department of Management Sciences, HEC Montréal, 3000 Chemin de la Côte-Ste-Catherine, Montréal, Québec, Canada H3T 2A7. Tel. : 514 340-6488 ; Fax : 514 340-5634

denis.larocque@hec.ca

Normandin : Corresponding author. Department of Economics and CIRPÉE, HEC Montréal, 3000 Chemin de la Côte-Ste-Catherine, Montréal, Québec, Canada H3T 2A7. Tel. : 514 340-6841; Fax: 514 340-6469

michel.normandin@hec.ca

Bouaddi acknowledges financial support from IFM2, Larocque thanks NSERC and HEC Montréal, and Normandin thanks SSHRC and HEC Montréal. 


\begin{abstract}
:
This paper analyzes the empirical relations between equity premia and state-dependent consumption and market risks. These relations are derived from a flexible specification of the CCAPM with mixture distribution, which admits the existence of two regimes. Focusing on the market return, we find that the consumption and market risks are priced in each state, and the responses of expected equity premia to these risks are state dependent. Extending to various portfolio returns, we show that the responses to downside consumption risks are the most important, they are almost always statistically larger than the responses to upside consumption risks, and they are much larger for firms having smaller sizes and facing more financial distresses.
\end{abstract}

Keywords: Mixture of truncated normals, Downside and upside consumption and market risks

JEL Classification: C16, G12 


\section{Introduction}

A central research agenda in financial economics is the understanding of the relation between equity premia and systematic risks. In this spirit, the Consumption-based Capital Asset Pricing Model (CCAPM) establishes that the response of expected equity premia to the relevant risk corresponds to the coefficient of relative risk aversion, where this response reflects the price of risk, or synonymously, the increase in stock returns required to compensate investors to a one-unit increase in risk. Here, the risk is entirely summarized by the consumption risk, that is, the covariance between asset returns and consumption change.

From an economic perspective, the CCAPM relies on both fundamental and auxiliary assumptions. The fundamental economic assumptions state that agents trade in a frictionless economy and choose consumption and stock holdings to maximize a Von NeumannMorgenstern utility, specified from an isoelastic function of consumption (e.g. Hansen and Singleton 1982). The auxiliary distributional assumptions stipulate that (log) consumption changes and $(\log )$ stock returns are jointly governed by a normal distribution (e.g. Hansen and Singleton 1983).

This paper attempts to enrich the relation between equity premia and risks, by allowing for the possibility that risks are state dependent and capture additional sources of uncertainty than just the consumption risk. For this purpose, our strategy is to preserve the baseline economic assumptions of the CCAPM in order to gauge solely the effects of relaxing the auxiliary normal hypothesis by using flexible, yet tractable, distributional assumptions. This strategy substantially departs from a vast literature that amends agents' preferences, but, in empirical implementations, usually maintained the normality assumption. ${ }^{1}$

1 Examples include habit formations (e.g. Campbell and Cochrane 1999; Constandinides 1990), social status (e.g. Bakshi and Chen 1996), disappointments (e.g. Gul 1991), preferences for certain regimes or for the timing of uncertainty resolution (e.g. Gordon and St-Amour 2000; Epstein and Zin 1991), and taste shocks (e.g. Normandin and St-Amour 1998). 
Importantly, the adoption of a flexible distribution is motivated by the overwhelming empirical evidence against the validity of the normal distribution. For example, the consumption change and stock returns display negative skewness and positive excess kurtosis (e.g. Balke and Fomby 1994). Also, the covariances between asset returns exhibit asymmetries (e.g. Bekaert and Wu 2000; Kroner and Ng 1998; Conrad, Gultekin, and Kaul 1991), and their correlations are substantially larger for downside movements of stock returns than for upside ones (e.g. Ang and Chen 2002; Longin and Solnik 2001). These asymmetries translate into betas that are generally larger in bear markets than in bull markets (e.g. Ang, Chen, and Xing 2006; Braun, Nelson, and Sunier 1995; Ball and Kothari 1989).

In our application, we specify a mixture of truncated joint normal distributions which admits the existence of two distinct regimes. Specifically, the unfavorable (favorable) state occurs when the market return is smaller or equal (larger) than a certain threshold. Note that this definition of the regimes is appealing given that the state variable, corresponding to the market return, represents a systematic risk and is often selected in previous studies (e.g. Butler and Joaquin 2002; Longin and Solnik 2001). Also, the mixture distribution offers several advantages. First, it is tractable since switches across regimes are defined from a single state variable that is observable. This contrasts with previous analyses of asset return behavior based on Markov switching processes, which involve latent state variables (e.g. Cecchetti, Lam, and Mark 1993, 1990; Kandel and Stambaugh 1990). Second, the mixture distribution nests various existing distributions. Examples include multivariate normal distributions and univariate truncated normal distributions, where the threshold coincides with the mode of the variable (e.g. John 1982). Third, the mixture distribution is flexible enough to represent a broad class of distributions. In particular, the consumption change and asset returns may exhibit excess kurtosis, skewness, and rich patterns of dependence across states. Such dependence allows for the existence of state- 
dependent risks, where the downside (upside) risks are measured from the semi-covariances capturing the comovements of the relevant variables within the unfavorable (favorable) state.

We next combine the mixture distribution with the conventional economic environment to derive an analytical solution for expected equity premia. This leads to a flexible specification of the CCAPM that nests the solution obtained from a normal distribution, and that accounts for the deviations of expected asset returns from their modes as well as for the deviations of the comovements between asset returns and consumption change across the two states. The flexible CCAPM establishes rich relations between expected equity premia and state-dependent risks, as illustrated from plausible parametrizations of the mixture distribution. In particular, the responses of expected equity premia to the relevant risks are larger in the unfavorable state than in the favorable one. This reflects the notion that larger risk premia are required to compensate downside risks than upside risks. Also, the responses to downside risks are always positive, whereas the responses to upside risks are sometimes negative. This last feature suggests that compensations may be negative because an increase of upside risks tends to increase the spread of values for asset returns within the favorable state, which, in turn, allows for the possibility of larger returns. Finally, the CCAPM with mixture distribution implies that the relevant sources of systematic risks are the state-dependent consumption and market risks, that is, the semi-covariances of asset returns with consumption change and market return.

Empirically, we estimate the parameters involved in the CCAPM with mixture distribution for monthly post-1960 U.S. data. Given the large number of parameters, we sequentially estimate different subsets of parameters by maximum likelihood conditional on given values for the remaining parameters, to ultimately estimate jointly all parameters. These estimates are then used to measure the responses of expected equity premia to consumption 
and market risks in each state, where these risks are evaluated from the relevant semicovariances. We finally compute the covariance matrix of the estimates of the responses and risks by applying a bootstrap method. This allows us to test whether the responses to consumption and market risks are statistically different across states, and whether risks are state dependent.

We start our empirical investigation by focusing exclusively on the relations between a global-index return and state-dependent risks. We find that the estimates of the responses of expected excess market return to consumption and market risks are positive in each state, except for the upside market risk, and are always significant. This suggests that both the consumption and market risks are priced in each state. Also, the responses to downside consumption and market risks are statistically larger than the responses associated with the upside counterparts. This indicates that the responses to both consumption and market risks are state dependent. Finally, the consumption and market risks are always positive, mostly significant, and state dependent.

We then pursue our analysis by considering several extentions to study the relations between portfolio returns and state-dependent risks, where portfolios are sorted by size, book-to-market, and industry. We find that the dominant relations are those linking equity premia to downside consumption risks. Specifically, the estimates of the responses to these downside consumption risks are often significant. Moreover, these responses are much more frequently significant than any other responses associated with alternative sources of risks. In addition, the responses to downside consumption risks are most of the time statistically larger than the responses to upside consumption risks, and are much larger for firms having smaller sizes and facing more financial distresses. Note, however, that the wide range in the responses to downside consumption risks across portfolios arises despite that the levels of these risks are not much larger for smaller firms, for more financially 
fragile firms, or for specific industries.

This paper is organized as follows. Section 2 presents the properties of the mixture distribution. Section 3 derives the relation between equity premia and state-dependent risks from the CCAPM with mixture distribution. Section 4 outlines the estimation method. Section 5 reports the basic results focusing on the links between a global-index return and state-dependent risks. Section 6 presents extensions to understand the behavior of returns across various portfolios. Section 7 concludes.

\section{Mixture Distribution}

This section presents a flexible mixture distribution that nests the conventional normal distribution, which constitutes an auxiliary assumption frequently invoked to solve the CCAPM (e.g. Hansen and Singleton 1983). The mixture distribution will prove useful to analyze rich relations between equity premia and state-dependent risks. ${ }^{2}$

Specifically, the mixture distribution admits the existence of two distinct regimes. The first regime corresponds to an unfavorable state $(s=1)$ occuring when the market return is smaller or equal to a certain threshold. The second regime is a favorable state $(s=2)$ arising when the market return is larger than the threshold. This definition of the regimes is appealing for a number of reasons. First, the unfavorable and favorable states may be interpreted as bear and bull markets. Second, the state variable corresponding to the market return represents a systematic risk, since the market portfolio fully diversifies idiosynchratic risks. Third, our unique state variable provides a parcimonious representation of multiple state variables corresponding to individual asset returns, given that the market return is a linear combinations of all individual returns. Fourth, our selection of the state

2 The technical details behind the derivations of the properties of the mixture distribution are relegated to the Appendix. 
variable is analogous to that find in several previous studies (e.g. Butler and Joaquin 2002; Longin and Solnik 2001), and is consistent with the cases where specific portfolio or individual returns constitute the state variables (e.g. Ang and Chen 2002).

Formally, we use a mixture of truncated normal distributions. To do so, we first form the unconditional density (relative to the states) of the variables by summing across states the joint density function of the variables and the states:

$$
f\left(\mathbf{X}_{t+1} \mid \boldsymbol{\Omega}_{\mathbf{t}} ; \boldsymbol{\Theta}\right)=\pi_{1} f\left(\mathbf{X}_{t+1} \mid s_{t+1}=1, \boldsymbol{\Omega}_{t} ; \boldsymbol{\Theta}\right)+\pi_{2} f\left(\mathbf{X}_{t+1} \mid s_{t+1}=2, \boldsymbol{\Omega}_{t} ; \boldsymbol{\Theta}\right) .
$$

The vector of variables is $\mathbf{X}_{t+1}=\left[x_{i, t+1}\right]$, with $i=1, \ldots, n, c, m$ and $n=(N-1)$. Here, $x_{c, t+1}$ is the $(\log )$ consumption change, $x_{m, t+1}$ is the $(\log )$ return of the market portfolio, and $x_{i, t+1}$ is the $(\log )$ return of asset $i$, with $i=1, \ldots, n$. Note that the return of the $N$ th asset is excluded to avoid a perfect multicolinearity between the market return and individual returns. The vector $\boldsymbol{\Theta}$ includes population parameters.

We then specify the conditional density function to that associated with a truncated normal distribution:

$$
f\left(\mathbf{X}_{t+1} \mid s_{t+1}=s, \boldsymbol{\Omega}_{\mathbf{t}} ; \boldsymbol{\Theta}\right)=\frac{I_{s, t+1}}{(2 \pi)^{(n+2) / 2}\left|\boldsymbol{\Sigma}_{s}\right|^{1 / 2} k_{s}} \exp \left[-\frac{1}{2}\left(\mathbf{X}_{t+1}-\boldsymbol{\Lambda}\right)^{\prime} \boldsymbol{\Sigma}_{s}^{-1}\left(\mathbf{X}_{t+1}-\boldsymbol{\Lambda}\right)\right] .
$$

The vector $\boldsymbol{\Lambda}=\left[\lambda_{i}\right]$ contains the modes of each variable. The positive definite scaling matrix $\boldsymbol{\Sigma}_{s}=\left[\sigma_{s, i j}\right]$ may be specific to the state, where $s=1,2$ and $i, j=1, \ldots, n, c, m$. The indicator function $I_{s, t+1}$ takes the value one in state $s$ and zero otherwise. For example, $I_{1, t+1}=1$ when $r_{m, t+1} \leq \tau$ and $I_{2, t+1}=1$ as long as $r_{m, t+1}>\tau$, where $\tau$ is the threshold. The constant $k_{s}=\left[(s-1)-(-1)^{s} F\left(\frac{\delta}{\sqrt{\sigma_{s, m m}}}\right)\right]$ normalizes the cumulative distribution 
function associated with (2) to unity, where $F\left(\frac{\delta}{\sqrt{\sigma_{s, m m}}}\right)$ is the cumulative distribution function of the standard normal distribution and $\delta=\left(\tau-\lambda_{m}\right)$ is the differential between the threshold and the mode of the market return.

Also, it can be shown that the unconditional probability (relative to the states) of being in state $s$ corresponds to:

$$
\pi_{s}=\frac{k_{s}\left|\boldsymbol{\Sigma}_{s}\right|^{1 / 2}}{k_{1}\left|\boldsymbol{\Sigma}_{1}\right|^{1 / 2}+k_{2}\left|\boldsymbol{\Sigma}_{2}\right|^{1 / 2}} .
$$

Note that the mixture distribution nests the conventional normal distribution when the restrictions $\delta=0$ and $\boldsymbol{\Sigma}=\boldsymbol{\Sigma}_{1}=\boldsymbol{\Sigma}_{2}$ are imposed. In this case, $f\left(\mathbf{X}_{t+1} \mid \boldsymbol{\Omega}_{\mathbf{t}} ; \boldsymbol{\Theta}\right)=$ $\frac{1}{(2 \pi)^{(n+2) / 2}|\boldsymbol{\Sigma}|^{1 / 2}} \exp \left[-\frac{1}{2}\left(\mathbf{X}_{t+1}-\boldsymbol{\Lambda}\right)^{\prime} \boldsymbol{\Sigma}^{-1}\left(\mathbf{X}_{t+1}-\boldsymbol{\Lambda}\right)\right], \quad f\left(\mathbf{X}_{t+1} \mid s_{t+1}=s, \boldsymbol{\Omega}_{\mathbf{t}} ; \boldsymbol{\Theta}\right)=$ $\frac{I_{s, t+1}}{(2 \pi)^{(n+2) / 2}|\boldsymbol{\Sigma}|^{1 / 2}} \exp \left[-\frac{1}{2}\left(\mathbf{X}_{t+1}-\boldsymbol{\Lambda}\right)^{\prime} \boldsymbol{\Sigma}^{-1}\left(\mathbf{X}_{t+1}-\boldsymbol{\Lambda}\right)\right]$, and $\pi_{s}=1 / 2$, where the expected value of each variable is equal to its mode and the covariance matrix corresponds to the scaling matrix.

Some properties of the mixture distribution are summarized by the unconditional moments (relative to the states). The first and second moments are:

$$
\begin{aligned}
E\left[\mathbf{X}_{t+1} \mid \boldsymbol{\Omega}_{t}\right] & =\boldsymbol{\Lambda}-\boldsymbol{\Xi} \\
\boldsymbol{\Upsilon} & =\pi_{1} \boldsymbol{\Sigma}_{1}+\pi_{2} \boldsymbol{\Sigma}_{2}-\boldsymbol{\Xi} \boldsymbol{\Xi}^{\prime}-\frac{1}{\sqrt{2 \pi}}\left[\frac{\pi_{1} \eta_{1} \delta}{\sqrt{\sigma_{1, m m}}} \boldsymbol{\Psi}_{1} \boldsymbol{\Psi}_{1}^{\prime}-\frac{\pi_{2} \eta_{2} \delta}{\sqrt{\sigma_{2, m m}}} \boldsymbol{\Psi}_{2} \boldsymbol{\Psi}_{2}^{\prime}\right]
\end{aligned}
$$

where $\boldsymbol{\Upsilon}=E\left[\left(\mathbf{X}_{t+1}-E\left[\mathbf{X}_{t+1} \mid \boldsymbol{\Omega}_{t}\right]\right)\left(\mathbf{X}_{t+1}-E\left[\mathbf{X}_{t+1} \mid \boldsymbol{\Omega}_{t}\right]\right)^{\prime} \mid \boldsymbol{\Omega}_{t}\right]=\left[v_{i j}\right], \boldsymbol{\Xi}=\frac{1}{\sqrt{2 \pi}}$ $\left[\pi_{1} \eta_{1} \boldsymbol{\Psi}_{1}-\pi_{2} \eta_{2} \boldsymbol{\Psi}_{2}\right], \boldsymbol{\Psi}_{s}=\left[\frac{\sigma_{s, i m}}{\sqrt{\sigma_{s, m m}}}\right]$, and $\eta_{s}=\left[\exp \left(-\frac{1}{2} \frac{\delta^{2}}{\sigma_{s, m m}}\right)\right] / k_{s}$. Note that imposing the restrictions $\delta=0$ and $\boldsymbol{\Sigma}=\boldsymbol{\Sigma}_{1}=\boldsymbol{\Sigma}_{2}$ associated with the normal distribution confirms that $E\left[\mathbf{X}_{t+1} \mid \boldsymbol{\Omega}_{t}\right]=\boldsymbol{\Lambda}$ and $\boldsymbol{\Upsilon}=\boldsymbol{\Sigma}$. In general, relaxing these restrictions may imply that 
the expected value of a variable is smaller or larger than its mode. Also, the variances of the variables may be smaller or larger than those obtained from the normal case. Finally, the covariances between the variables may display the same or opposite signs than those related to the normal distribution.

The notion of state dependence is highlighted from the semi-moments, which are defined as the conditional moments (relative to the states). The first and second semi-moments are:

$$
\begin{aligned}
E\left[\mathbf{X}_{t+1} \mid s_{t+1}, \boldsymbol{\Omega}_{t}\right] & =\boldsymbol{\Lambda}+(-1)^{s} \frac{\eta_{s}}{\sqrt{2 \pi}} \boldsymbol{\Psi}_{s}, \\
\mathbf{\Upsilon}_{s} & =\boldsymbol{\Sigma}_{s}+\frac{\eta_{s}}{\sqrt{2 \pi}}\left[\frac{\eta_{s}}{\sqrt{2 \pi}}-(-1)^{s} \frac{\delta}{\sqrt{\sigma_{s, m m}}}\right] \boldsymbol{\Psi}_{s} \boldsymbol{\Psi}_{s}^{\prime},
\end{aligned}
$$

where $\boldsymbol{\Upsilon}_{s}=E\left[\left(\mathbf{X}_{t+1}-E\left[\mathbf{X}_{t+1} \mid s_{t+1}, \boldsymbol{\Omega}_{t}\right]\right)\left(\mathbf{X}_{t+1}-E\left[\mathbf{X}_{t+1} \mid s_{t+1}, \boldsymbol{\Omega}_{t}\right]\right)^{\prime} \mid s_{t+1}, \boldsymbol{\Omega}_{t}\right]=\left[v_{s, i j}\right]$. The restrictions $\delta=0$ and $\boldsymbol{\Sigma}=\boldsymbol{\Sigma}_{1}=\boldsymbol{\Sigma}_{2}$ impose that the expected values of the variables within each state are at equidistances from their modes, whereas the variances and covariances within each state are identical. The latter property implies that the semi-covariance between the asset return and consumption change is the same across states. This reflects a state-independent consumption risk, which is the unique source of systematic risk in the standard CCAPM. Likewise, the semi-covariance between the asset return and the market return is state independent. As will be discussed in the next section, the market risk represents an additional source of systematic risk in our application.

In contrast, relaxing the restrictions related to the normal distribution yields semicovariances that may differ across states. In such a case, the consumption and market risks become state dependent. Importantly, these state-dependent risks allow us to distinguish between downside and upside risks. That is, downside (upside) consumption and 
market risks are measured from the semi-covariances capturing the comovements of the relevant variables within the unfavorable (favorable) state. Interestingly, our measures of downside and upside risks accord with the notion that risks may be adequately captured by the second semi-moments, as highlighted in pioneer work (e.g. Markowitz 1959). Also, our measures of downside risks represent a specific application of the notion of co-lower partial moments (e.g. Bawa and Lindenberg 1977).

The mixture distribution offers several advantages. First, it is tractable since switches across regimes are defined from a single state variable that is observable. This constrasts with Markov switching processes, which involve latent state variables (e.g. Hamilton 1989). As mentioned above, such processes have been used in previous work to document statedependent risks.

Second, the mixture distribution nests some existing distributions. For exemple, it encompasses mixtures of univariate truncated normal distributions, for which the threshold coincides with the mode of the variable (e.g. John 1982). Importantly, our multivariate extension is required to measure state-dependent downside and upside risks through the appropriate semi-covariances. Also, as shown above our mixture distribution generalizes the conventional normal distribution, which is often used in the CCAPM to relate equity premia to state-independent measures of risk.

Third, the mixture distribution is flexible enough to represent a broad class of distributions. For expositional purposes, consider standardized bivariate distributions for the market return (i.e. the state variable) and an other variable. ${ }^{3}$ The other variable may be the consumption change, so that the dependence between the variables provides information

3 The standardization is performed by defining the vector of variables $\mathbf{W}_{t+1}=\boldsymbol{\Phi}^{-1}$ $\left(\mathbf{X}_{t+1}-E\left[\mathbf{X}_{t+1} \mid \boldsymbol{\Omega}_{t}\right]\right)$ - where $\mathbf{\Phi}$ is the Choleski factorization of $\boldsymbol{\Upsilon}$, while $E\left[\mathbf{X}_{t+1} \mid \boldsymbol{\Omega}_{t}\right]$ and $\boldsymbol{\Upsilon}$ are computed from (4) and (5) for $\delta=0, \boldsymbol{\Lambda}=\mathbf{0}$, and various parametrizations of $\boldsymbol{\Sigma}_{1}$ and $\boldsymbol{\Sigma}_{2}$. 
on the consumption risk for the market portfolio. Alternatively, the other variable may be an individual asset return, such that the dependence between the variables is related to the market risk for the individual asset. As is well known, the standardized normal distribution implies that the variables display no excess kurtosis, no skewness, and no dependence in every state. The latter feature translates into the absence of consumption or market risk in all regimes. In contrast, Figure 1 illustrates from some parametrizations that the standardized mixture distribution often implies that the variables exhibit excess kurtosis, skewness, and rich patterns of dependence across states. For exemple, although the unconditional covariance between the variables is null, a positive semi-covariance may occur only in one of the states. This translates into the presence of a consumption or market risk in one regime, and in the absence of risk in the other regime. Another pattern takes the form of a positive semi-covariance in the unfavorable or favorable state and a negative semi-covariance in the other state. This yields a positive consumption or market risk in one regime and a negative risk in the other regime. Of course, other parametrizations lead to other patterns of consumption or market risk across states.

\section{Equity Premia}

This section derives the relation between equity premia and state-dependent risks. For this purpose, we solve the CCAPM for an environment that preserves the usual fundamental economic assumptions, but relaxes the conventional auxiliary assumption that the variables are normally distributed. ${ }^{4}$

The economic assumptions postulate that an infinitely-lived representative agent is characterized by Von Neumann-Morgenstern preferences, where the time-period utility is an isoelastic function of consumption (e.g. Hansen and Singleton 1982). In this environment,

\footnotetext{
4 The solution is fully detailed in the Appendix.
} 
the optimal choices of consumption and asset portfolio shares lead to the Euler equation:

$$
1=E\left[\beta\left(\frac{C_{t+1}}{C_{t}}\right)^{-\alpha} R_{i, t+1} \mid \boldsymbol{\Omega}_{t}\right] .
$$

The term $E$ denotes the expectation operator and $\boldsymbol{\Omega}_{t}$ is the set of information available in period $t$. The variable $C_{t}$ represents consumption and $R_{i, t+1}$ is the gross return of individual asset $i$. These variables are used to construct $x_{c, t+1}=\left(\log C_{t+1}-\log C_{t}\right)$, the $(\log )$ consumption change, $x_{i, t+1}=\log R_{i, t+1}$, the $(\log )$ return of asset $i, x_{f, t+1}=$ $\log R_{f, t+1}$, the (log) return of the riskfree asset, and $x_{m, t+1}=\log R_{m, t+1}$, the (log) return of the market portfolio. The parameter $\beta$ is the discount factor and $\alpha$ is the relative risk aversion. Equation (8) holds for each risky asset, the riskfree asset, and the market portfolio.

To solve the expectation involved in (8), we depart from the standard approach which imposes that the consumption change and asset returns jointly follow a normal distribution (e.g. Hansen and Singleton 1983). Instead, we use the flexible mixture distribution (1)-(3) to obtain an analytical solution for expected equity premia. For asset $i$, the solution takes the form:

$$
\begin{aligned}
E\left[x_{i, t+1}^{e} \mid \boldsymbol{\Omega}_{t}\right] & =\left[-\frac{\sigma_{1, i i}}{2}+\alpha \sigma_{1, i c}\right]-\left[\frac{1}{\sqrt{2 \pi}}\left(\pi_{1} \eta_{1} \frac{\sigma_{1, i m}}{\sqrt{\sigma_{1, m m}}}-\pi_{2} \eta_{2} \frac{\sigma_{2, i m}}{\sqrt{\sigma_{2, m m}}}\right)\right] \\
& -\left[\log \left(1+\frac{\pi_{2} \phi_{2, i}}{\pi_{1} \phi_{1, i}} \exp \left(\frac{1}{2}\left(\sigma_{2, i i}-\sigma_{1, i i}\right)+\frac{\alpha^{2}}{2}\left(\sigma_{2, c c}-\sigma_{1, c c}\right)-\alpha\left(\sigma_{2, i c}-\sigma_{1, i c}\right)\right)\right)\right] \\
& +\left[\log \left(1+\frac{\pi_{2} \phi_{2, f}}{\pi_{1} \phi_{1, f}} \exp \left(\frac{\alpha^{2}}{2}\left(\sigma_{2, c c}-\sigma_{1, c c}\right)\right)\right)\right]+\left[\log \phi_{1, f}-\log \phi_{1, i}\right]
\end{aligned}
$$

Here, the excess return $x_{i, t+1}^{e}=x_{i, t+1}-x_{f, t+1}$ corresponds to the equity premium of asset $i$, $\phi_{s, i}=\left[(s-1)-(-1)^{s} F\left(\frac{\delta+\alpha \sigma_{s, c m}-\sigma_{s, i m}}{\sqrt{\sigma_{s, m m}}}\right)\right] / k_{s}$, and $\phi_{s, f}=\left[(s-1)-(-1)^{s} F\left(\frac{\delta+\alpha \sigma_{s, c m}}{\sqrt{\sigma_{s, m m}}}\right)\right] / k_{s}$. 
Evaluating expression (9) under the restrictions $\delta=0$ and $\boldsymbol{\Sigma}=\boldsymbol{\Sigma}_{1}=\boldsymbol{\Sigma}_{2}$ associated with the normal distribution yields the conventional solution of the CCAPM: $E\left[x_{i, t+1}^{e} \mid \boldsymbol{\Omega}_{t}\right]=$ $\left[-\frac{\sigma_{i i}}{2}+\alpha \sigma_{i c}\right]$. In general, equation (9) leads to a flexible specification of the CCAPM that includes a term (between the first set of brackets) which is similar to the conventional solution and other terms (between the other sets of brackets) which highlight various deviations. For example, the expression between the second set of brackets reflects the deviation of the expected asset return to its mode. Also, the term between the third set of brackets captures the effect on the expected asset return of the deviations in movements and comovements of return and consumption change between the two states. Likewise, the expression between the fourth set of brackets measures the effect on the riskfree rate of the deviation in fluctuations of consumption change across regimes.

Importantly, the relevant sources of risk depend on the distributional assumptions. For example, the CCAPM with normal distribution predicts that the risk is entirely captured by a state-independent consumption risk. This is confirmed by noting that $v_{i c}=\sigma_{i c}$, as obtained by evaluating (5) under the restrictions $\delta=0$ and $\boldsymbol{\Sigma}=\boldsymbol{\Sigma}_{1}=\boldsymbol{\Sigma}_{2}$. In contrast, the CCAPM with mixture distribution implies that the relevant risks are the state-dependent consumption and market risks. To see this, note that expression (9) involves the parameters $\sigma_{s, i c}, \sigma_{s, i m}, \sigma_{s, m c}, \sigma_{s, m m}$, and $\delta$, and equation (7) establishes that the consumption and market risks in regime $s$ are determined by these parameters.

Moreover, the relation between equity premia and risks is affected by the distributional assumptions. Specifically, the CCAPM with normal distribution implies that the expected excess return is linear in the state-independent consumption risk, so that its response to this risk is constant. In contrast, the CCAPM with mixture distribution leads to a highly non-linear function in state-dependent consumption and market risks, and as such the response of expected excess return to each source of risk is not a fixed proportion. 
Figure 2 and 3 illustrate the rich relations between expected equity premia and statedependent risks from plausible parametrizations of the mixture distribution. ${ }^{5}$ Figure 2 indicates that the expected equity premium raises as either the downside or upside consumption risk increases. However, the increase of the expected excess return is much more pronounced when the downside consumption risk increases than when the upside consumption risk increases. Figure 3 reveals that the expected equity premium raises when the downside market risk increases, but decreases as the upside market risk increases.

It will prove useful to summarize these relations by the responses of expected excess return to each source of risks in a given state. Formally, for asset $i$ the response to the consumption risk in state $s$ is defined as

$$
\begin{aligned}
& \rho_{s, i c}= \\
& \frac{\left[\frac{\partial E\left[x_{i, t+1}^{e} \mid \boldsymbol{\Omega}_{t}\right]}{\partial \sigma_{s, i c}} d \sigma_{s, i c}+\frac{\partial E\left[x_{i, t+1}^{e} \mid \boldsymbol{\Omega}_{t}\right]}{\partial \sigma_{s, i m}} d \sigma_{s, i m}+\frac{\partial E\left[x_{i, t+1}^{e} \mid \boldsymbol{\Omega}_{t}\right]}{\partial \sigma_{s, m c}} d \sigma_{s, m c}+\frac{\partial E\left[x_{i, t+1}^{e} \mid \boldsymbol{\Omega}_{t}\right]}{\partial \sigma_{s, m m}} d \sigma_{s, m m}+\frac{\partial E\left[x_{i, t+1}^{e} \mid \boldsymbol{\Omega}_{t}\right]}{\partial \delta} d \delta\right]}{\left[\frac{\partial v_{s, i c}}{\partial \sigma_{s, i c}} d \sigma_{s, i c}+\frac{\partial v_{s, i c}}{\partial \sigma_{s, i m}} d \sigma_{s, i m}+\frac{\partial v_{s, i c}}{\partial \sigma_{s, m c}} d \sigma_{s, m c}+\frac{\partial v_{s, i c}}{\partial \sigma_{s, m m}} d \sigma_{s, m m}+\frac{\partial v_{s, i c}}{\partial \delta} d \delta\right]}
\end{aligned}
$$

and the response to the market risk in regime $s$ is

$$
\rho_{s, i m}=\frac{\left[\frac{\partial E\left[x_{i, t+1}^{e} \mid \boldsymbol{\Omega}_{t}\right]}{\partial \sigma_{s, i m}} d \sigma_{s, i m}+\frac{\partial E\left[x_{i, t+1}^{e} \mid \boldsymbol{\Omega}_{t}\right]}{\partial \sigma_{s, m m}} d \sigma_{s, m m}+\frac{\partial E\left[x_{i, t+1}^{e} \mid \boldsymbol{\Omega}_{t}\right]}{\partial \delta} d \delta\right]}{\left[\frac{\partial v_{s, i m}}{\partial \sigma_{s, i m}} d \sigma_{s, i m}+\frac{\partial v_{s, m m}}{\partial \sigma_{s, m m}} d \sigma_{s, m m}+\frac{\partial v_{s, i m}}{\partial \delta} d \delta\right]} .
$$

5 Specifically, the expected excess market return as well as the consumption and market risks in each state are constructed by evaluating equations (9) and (7) from various values in the neibourghood of the estimates of the parameters $\left(\boldsymbol{\Sigma}_{\mathbf{1}}, \boldsymbol{\Sigma}_{\mathbf{2}}\right.$, and $\left.\delta\right)$ involved in the relevant second semi-moments and values for the remaining parameters $\left(\alpha\right.$ and $\left.\lambda_{c}\right)$ that are calibrated to their estimated values. The estimates of the parameters are obtained for a bivariate specification including the excess market return and consumption change (see Section 5). 
The numerator and denominator in (10) are the differentials of the expected excess return and of the consumption risk in state $s$ with respect to changes in the parameters involved in the semi-covariance between the asset return and consumption change in regime $s$ where the expected excess return and state-dependent consumption risk are given in (9) and (7). Accordingly, expression (10) measures the response of expected equity premium to an infinitesimal change in the consumption risk in state $s$. Similarly, equation (11) measures the response of expected excess asset return to an infinitesimal change in the market risk in state $s .^{6}$

For the CCAPM with normal distribution, equations (10) and (11) reduce to $\rho_{1, i c}=\rho_{2, i c}=$ $\alpha$ and $\rho_{1, i m}=\rho_{2, i m}=0$. Note that these constant responses are state independent. Specifically, the response to the consumption risk in each state corresponds to the relative risk aversion. As is well known, this term captures the price of consumption risk, that is, the change in the risk premium required to compensate investors when the covariance between the asset return and consumption change increases by one unit. Also, the response to the market risk in each state is null. This confirms that this type of risk is never priced.

When the CCAPM with mixture distribution is evaluated under the parametrizations used in Figures 2 and 3, the responses display the following signs and magnitudes: $\rho_{1, i c}>$ $\rho_{2, i c}>0, \rho_{1, i m}>0$, and $\rho_{2, i m}<0$. These results have three economic implications. First, all responses are non-null, which implies that both the consumption and market risks are priced. Second, the responses are state dependent. In particular, the responses to the consumption and market risks are larger in the unfavorable state than in the favorable one. This reflects the intuitive notion that a larger risk premium is required to compensate

6 For the response of expected excess market return, the partial derivatives in (10) and (11) are first obtained by using (9) and (7) for $i \neq m$, and are then evaluated for $\sigma_{s, i j}=\sigma_{s, m m}$ and $\sigma_{s, i c}=\sigma_{s, m c}$ (where $i, j=1, \ldots, n, m$ ). 
a downside risk than an upside risk. Third, the response to the upside market risk is negative. This implies that there is a negative compensation following an increase of the comovement between asset and market returns within the favorable state. Intuitively, this occurs because such a larger comovement tends to increase the spread of values for the asset return within the favorable state, thus, making possible the realization of a larger return.

\section{Estimation Strategy}

This section outlines the empirical method that we apply to analyze the relation between equity premia and risks. This method includes three blocks. In the first block, we estimate the parameters involved in the CCAPM with mixture distribution. In the second block, we use these estimates to measure the consumption and market risks as well as the responses of expected excess returns to these risks. In the third block, we compute the covariance matrix of the estimates of the risks and the responses. This will allow us to test whether the consumption and market risks are statistically different across states, and whether the responses are state-dependent.

Specifically, the first block is a maximum-likelihood estimation procedure. For this purpose, the sample log likelihood is evaluated from the following expression:

$$
\log L(\boldsymbol{\Theta})=\sum_{t=1}^{T} \log f\left(\mathbf{X}_{t+1} \mid \mathbf{\Omega}_{t} ; \boldsymbol{\Theta}\right)
$$

where the joint density function is given by (1)-(3) and $T$ is the sample size.

In practice, it will prove useful to evaluate equation (12) from the observations on excess returns $\left(x_{i, t+1}^{e}\right)$, rather than from data on the returns of assets $\left(x_{i, t+1}\right)$. To this end, the deviations of asset returns from their modes in the truncated normal distribution (2) are rewritten as: 


$$
\begin{aligned}
x_{i, t+1}-\lambda_{i} & =x_{i, t+1}-E\left[x_{i, t+1} \mid \mathbf{\Omega}_{t}\right]-\frac{1}{\sqrt{2 \pi}}\left[\pi_{1} \eta_{1} \frac{\sigma_{1, i m}}{\sqrt{\sigma_{1, m m}}}-\pi_{2} \eta_{2} \frac{\sigma_{2, i m}}{\sqrt{\sigma_{2, m m}}}\right] \\
& =x_{i, t+1}^{e}-\left[-\frac{\sigma_{1, i i}}{2}+\alpha \sigma_{1, i c}\right] \\
& +\left[\log \left(1+\frac{\pi_{2} \phi_{2, i}}{\pi_{1} \phi_{1, i}} \exp \left(\frac{1}{2}\left(\sigma_{2, i i}-\sigma_{1, i i}\right)+\frac{\alpha^{2}}{2}\left(\sigma_{2, c c}-\sigma_{1, c c}\right)-\alpha\left(\sigma_{2, i c}-\sigma_{1, i c}\right)\right)\right)\right] \\
& -\left[\log \left(1+\frac{\pi_{2} \phi_{2, f}}{\pi_{1} \phi_{1, f}} \exp \left(\frac{\alpha^{2}}{2}\left(\sigma_{2, c c}-\sigma_{1, c c}\right)\right)\right)\right]-\left[\log \phi_{1, f}-\log \phi_{1, i}\right]
\end{aligned}
$$

Equation (13) is obtained by substituting out the mode of the asset return from (4). Equation (14) is derived by substracting the riskfree rate from the actual and expected asset returns, and by substituting the expected excess return by the solution (9) of the CCAPM with mixture distribution.

Likewise, the criteria associated with the indicator functions in (2) are expressed in terms of the excess market return. For exemple, the criterion $x_{m, t+1} \leq \tau$ is rewritten as $\left(x_{m, t+1}-\right.$ $\left.\lambda_{m}\right) \leq \delta$, where the deviation $\left(x_{m, t+1}-\lambda_{m}\right)$ is obtained by evaluating (14) for $i=m$.

In our applications, the maximum-likelihood estimates are computed for the parameters involved in a bivariate specification as well as multivariate extensions. The bivariate case evaluates the deviation (14) for the excess market return $(i=m)$ and takes into account the deviation of consumption change from its mode. This case involves 9 parameters: 3 distinct elements in the scaling matrix $\boldsymbol{\Sigma}_{1}, 3$ distinct elements in $\boldsymbol{\Sigma}_{2}$, the differential $\delta$ between the threshold and the mode of the market return, the relative risk aversion $\alpha$, and the mode $\lambda_{c}$ of the consumption change. Also, each multivariate specification includes 6 equations: the deviations (14) for four excess portfolio returns $(i=1, \ldots, n$ with $n=4)$ and for the excess market return $(i=m)$, as well as the deviation of the consumption change from its mode. Hence, each multivariate specification involves 45 parameters.

Admittedly, estimating as many parameters is a challenging task. To circumvent this 
difficulty, we sequentially estimate different subsets of parameters by maximizing the likelihood function (12) conditional on given values for the remaining parameters, to ultimately estimate jointly all parameters. This procedure is described by the following four steps.

Step 1. The distinct elements of $\boldsymbol{\Sigma}_{1}$ and $\boldsymbol{\Sigma}_{2}$ and the parameter $\lambda_{c}$ are estimated, given fixed values for $\alpha$ and $\delta$. For this purpose, we initiate $\boldsymbol{\Sigma}_{1}=\boldsymbol{\Sigma}_{2}$ to the sample covariance matrix of the variables involved in the specification, we use the starting value $\lambda_{c}=0$, and we fix the remaining parameters to $\alpha=25$ and $\delta=0$.

Step 2. The relative risk aversion $\alpha$ is estimated, for given values for all other parameters. To this end, we use 50 different starting values for $\alpha$, which are uniformly split over the range between 1 and 50. Also, these starting values are combined with 201 different fixed values for $\delta$, which are uniformly spread out over the interval -1 and 1 . Moreover, for all cases the values for the elements of $\boldsymbol{\Sigma}_{1}$ and $\boldsymbol{\Sigma}_{2}$ and for the parameter $\lambda_{c}$ are fixed to the estimates found in Step 1.

Step 3. The elements of $\boldsymbol{\Sigma}_{1}$ and $\boldsymbol{\Sigma}_{2}$ as well as the parameters $\lambda_{c}$ and $\alpha$ are jointly estimated, conditional on fixed values for $\delta$. To do so, the starting values for $\boldsymbol{\Sigma}_{1}, \boldsymbol{\Sigma}_{2}$, and $\lambda_{c}$ are set to the estimates computed in Step 1. The starting values for $\alpha$ correspond to the estimates obtained in Step 2 for each point of the grid for $\delta$. Moreover, the parameter $\delta$ is fixed to various values by using the same grid as in Step 2 .

Step 4. All the parameters are jointly estimated. In this case, the relevant starting value for $\delta$ corresponds to the point of the grid which yields the largest log-likelihood value in Step 3. Also, the starting values for the remaining parameters are set to the estimates obtained in Step 3 for the relevant value of $\delta$.

In Steps 1 to 4, the estimates are computed by using the Nelder-Mead Simplex algorithm to maximize the log-likelihood function (12) under certain restrictions. ${ }^{7}$ Specifically, the

\footnotetext{
7 After several experiments, we have selected this algorithm because it outperforms the Newton-
} 
restrictions impose that the risk aversion $\alpha$ is positive, the matrices $\boldsymbol{\Sigma}_{1}$ and $\boldsymbol{\Sigma}_{2}$ are positive definite, and the number of observations in each state is at least 5 percent of the sample size. The latter restriction ensures that there are sufficient degrees of freedom in each state (i.e. at least 28 observations) to estimate the distinct elements in $\boldsymbol{\Sigma}_{1}$ and $\boldsymbol{\Sigma}_{2}$ (i.e. 3 and 21 parameters per state in the bivariate and multivariate specifications, respectively).

The second block of our empirical method measures the risks and the responses of expected equity premia to risks. In particular, the risks are obtained by evaluating the relevant second semi-moments (7) from the maximum-likelihood estimates of the parameters computed above. For example, for asset $i$ the downside and upside consumption risks $\left(v_{s, i c}\right)$ are measured from the estimates of the semi-covariances between the asset return and consumption change under the unfavorable and favorable states $(s=1,2)$. Likewise, the downside and upside market risks $\left(v_{s, i m}\right)$ correspond to the estimates of the semicovariances between the asset return and market return in each regime. In addition, the responses of expected excess return of asset $i$ to the consumption risk $\left(\rho_{s, i c}\right)$ and to the market risk $\left(\rho_{s, i m}\right)$ under the unfavorable and favorable states $(s=1,2)$ are estimated by evaluating (10) and (11) from the maximum-likelihood estimates of the parameters.

The last block of our approach constructs the covariance matrix for the estimates of risks and responses. Obviously, this is essential to statistically test whether the risks and responses are individually significant, and whether they are state dependent. In practice, we compute the covariance matrix of interest by applying the delta method. This, in turn, requires the covariance matrices of the maximum-likelihood estimates of the parameters involved in the bivariate and multivariate specifications. Given that these covariance matrices are not directly available since we use a Simplex algorithm, we compute these

Raphson method, the Newton-Raphson Ridge method, the Quasi-Newton method, the Double Dogleg method, the Conjugate Gradient method, and the Trust Region method. 
matrices by applying the bootstrap method. Specifically, we resample the series involved in the bivariate and multivariate specifications to generate 100 bootstrap samples, and, for each bootstrap sample, we apply the four-step maximum-likelihood procedure outlined above.

\section{Basic Results}

In this section, we assess the properties of the CCAPM with mixture distribution from a bivariate specification, which involves the excess market return and consumption change. For this purpose, we use monthly U.S. data covering the 1960-01 to 2007-12 period. The excess return is the difference between the (annualized) market return and riskfree rate. The market return is measured by the logarithm of the gross nominal value-weighted return (including dividends) associated with the global index of the NYSE, NASDAQ, and AMEX markets. The riskfree rate is approximated by the logarithm of the gross nominal rate on one-month Treasury bills. Also, the (annualized) consumption change is measured as the first difference of the logarithm of consumption. Consumption corresponds to the seasonally adjusted real personal expenditures on nondurable goods and services, normalized by the total population. ${ }^{8}$

As a useful starting point, Figure 4 documents the behavior of the risks and responses associated with various values for the differential $\delta$ (between the threshold and the mode of the market return), where $\delta$ is one of the key parameters of the mixture distribution. ${ }^{9}$ Visual inspection of the plots reveal that the consumption risk is systematically smaller

8 The series used to construct the excess market return are collected from the Center for Research in Security Prices. The series required to measure consumption change are released by the U.S. Department of Commerce (Bureau of Economic Analysis and Census Bureau).

9 The estimates of risks and responses are obtained from Step 3 of the maximum-likelihood procedure outlined in the previous section. For ease of interpretation, these estimates are smoothed from centered, equal-weighted moving averages with windows including fifteen entries. 
than the market risk in each regime. Apart from this characteristic, the consumption and market risks display similar patterns. For example, these risks are always positive in both the unfavorable and favorable states. Also, the downside risks are almost always larger than the upside risks, which suggests that the risks are state dependent for most values of the differential. Specifically, the downside consumption and market risks are around three times larger than their upside counterparts for small values of the differential, but are about the same size for large values of the differential. As a result, the downside (upside) consumption and market risks tend to decrease (increase) slowly in the differential over the horizon including small and intermediate values of the differential, and to decrease (increase) sharply for large values of the differential.

Regarding the compensations associated to different sources of uncertainty, note that the responses to consumption risks are almost always larger (in absolute values) than the responses to market risks. Otherwise, the responses to consumption and market risks share similar characteristics. More explicitly, these responses are always positive in the unfavorable state, whereas they are either positive or negative in the favorable state. Also, the responses to downside risks tend to be larger than the responses to upside risks, which implies that the responses are state dependent for certain values of the differential. In particular, the responses to downside consumption and market risks are large over the range including the smallest values of the differential, they decrease rapidly in the differential for small values of the differential, and they remain small or negligible for intermediate and large values of the differential. The responses to upside consumption and market risks depict a similar shape, except that the responses become negative over the horizon of intermediate and large values of the differential, and they converge toward zero over the range covering the largest values of the differential.

For many reasons, these findings are at odds with the predictions of the CCAPM with 
normal distribution. First, the consumption risks and the associated responses are most of the time state dependent, as they substantially differ across states over most values of the differential. Second, although the downside and upside consumption risks are occasionally about the same magnitudes under the largest values of the differential, the associated responses are negligible. Hence, time-independent consumption risk does not seem to be priced, and as such it may not be relevant to explain risk premia. Third, the responses to the upside and downside market risks are non-null for many values of the differential. This implies that not only the consumption risks, but also the market risks, may affect excess returns.

To pursue the analysis, Table 1 reports the joint estimates of all the parameters of the bivariate specifications involving the CCAPM with mixture distribution and with normal distribution. ${ }^{10}$ For the CAPM with mixture distribution, the estimates indicate that the consumption and market risks are always positive and are all significantly different from zero, with the exception of the upside consumption risk (for a level of significance of 10 percent). Also, the estimates of the downside consumption and market risks are larger than their upside counterparts, and the hypothesis of identical risks across the unfavorable and favorable states is statistically rejected for each source of uncertainty. This confirms that both consumption and market risks are state dependent.

In addition, the estimates reveal that the responses to consumption and market risks are positive, except for the response to the upside market risk, and are always significantly different from zero. This implies that both the consumption and market risks are priced in each state. Also, the estimates of the responses to downside consumption and market risks are larger than the responses associated with the upside counterparts, and the hypothesis of

10 These estimates are obtained by applying the entire estimation strategy explained in the previous section, including Step 4 of the maximum-likelihood procedure. 
identical responses across the two regimes is statistically rejected for each type of risk. This confirms that the responses to both consumption and market risks are state dependent.

For completeness, note that the estimates indicate that the semi-variances of consumption change are significant in each regime and are statistically different across states. Also, the estimate of the differential is positive and statistically different from zero. Likewise, the estimates of the risk aversion and the mode of consumption change are positive and significant.

In comparison, the estimates obtained for the CCAPM with normal distribution often substantially deviate from those just presented above. In particular, the estimates of the state-independent consumption and market risks largely undervalue the risks associated with the unfavorable state. Moreover, the estimate of the state-independent response to consumption risk, which corresponds to the relative risk aversion, largely overstates the responses to both downside and upside consumption risks. Finally, the state-independent response to market risk, which by construction is fixed to zero, underestimates the response to the downside market risk, and overpredicts the response to the upside counterpart.

Overall, the individual test results discussed so far overwelmingly reject the predictions of the CCAPM model with normal distribution highlighting that each type of risks and responses is state independent. In addition, performing a joint test leads to a strong rejection of the four restrictions imposed by the normal distribution: $\delta=0$ and $\boldsymbol{\Sigma}_{1}=\boldsymbol{\Sigma}_{2}$. Finally, the Akaike and Bayesian information criteria both confirm that the CCAPM with mixture distribution outperforms the CCAPM with normal distribution.

\section{Extensions}

This section extends the analysis of the CCAPM with mixture distribution from various 
multivariate specifications. Each specification includes the consumption change, the excess market return, and excess portfolio returns. As is common practice, five portfolios are formed by sorting returns either by size, book-to-market, or industry. For each portfolio group, the specification excludes the excess return of one portfolio to avoid a perfect multicolinearity between the excess portfolio returns and the excess market return. In practice, we exclude the excess portfolio return that displays the strongest correlation with the excess market return. The excess portfolio returns are measured by the difference between the (annualized) portfolio returns and the riskfree rate, where the portfolio returns are constructed from the logarithms of the gross nominal value-weighted returns (including dividends) for the NYSE, NASDAQ, and AMEX markets and cover the 1982:11 to 2007:11 period. ${ }^{11}$

Table 2 reports the estimates of each source of risks and the associated responses for size portfolios. The size criterion sorts firms based on their market-value equity (i.e. the number of shares outstanding times the price per share). The first quintile is a proxy of the smallest firms, whereas the fifth quintile corresponds to the largest firms. The excess return associated with the fourth quintile is excluded.

Interestingly, the estimates of the consumption and market risks associated with the various portfolios are systematically positive, they tend to decrease slightly in the size of firms, and they are all significantly different from zero (for a level of significance of 10 percent). Also, the estimates indicate that the downside consumption risks are always substantially larger than the upside consumption risks, while the downside market risks are slightly smaller than their upside counterparts. For every size portfolios, the hypothesis that risks are identical across the unfavorable and favorable regimes is statistically rejected for the

11 The portfolio returns are collected from the Fama-French data library, which is available from French's web page (http://mba.tuck.dartmouth.edu/pages/faculty/ken.french). 
consumption risks, but not for the market risks. This implies that the consumption risks are state dependent, while the market risks are state independent.

Moreover, the estimates of the responses to risks in the unfavorable state are almost always positive, they decrease substantially in the size of firms for consumption risks, but to a lesser extend for market risks, and they are systematically significant for consumption risks, but almost never for market risks. In contrast, the responses to consumption and market risks in the favorable regime are mostly negative, they usually increase modestly in the size of firms, and they are significant for about half of the cases. Also, the test results reveal that the responses to consumption risks are statistically different across regimes for most size portfolios, whereas the responses to market risks are state dependent for half of the cases.

Next, Table 3 presents the estimates of the risks and responses for growth portfolios. The growth criterion sorts firms based on their ratio of book-value equity to market-value equity. The first quintile is a proxy of firms experiencing the strongest growth, while the fifth quintile corresponds to firms facing the most important financial distresses. The excess return associated with the first quintile is excluded.

Note that the estimates of the consumption and market risks are always positive, they tend to increase moderatly in the book-to-market ratio, and they are statistically different from zero, except for some upside consumption risks. Also, the downside consumption risks are sizeably larger than the upside consumption risks, while the downside market risks are moderately smaller than their upside counterparts. However, the test results indicate that both the consumption and market risks are state independent.

In addition, the estimates of the responses to downside consumption risks are systematically positive, they increase substantially as firms face more financial distresses, and they 
are almost always statistically different from zero. Also, the responses to downside market risks are most of the time positive, but they do not exhibit a specific pattern with respect to the book-to-market ratio, and they are never significant. In contrast, the responses to upside consumption and market risks are frequently negative, they tend to increase slightly in the book-to-market ratio, but they are never significant. Finally, the estimates indicate that the responses to consumption risks become state dependent as firms experience more financial distresses, whereas the compensations to market risks always remain statistically identical across regimes.

Finally, Tables 4 reports the estimates for industry portfolios. The industry criterion sorts firms based on their four-digit Standard Industrial Classification (SIC) codes. The five industries are (1) Consumer (including durables, nondurables, whosales, and retail); (2) Manufacturing, Energy, and Utilities; (3) High-Tech (including business equipment, telephone, and television transmission); (4) Health (including healthcare, medical equipment, and drugs); and (5) Others. The excess return associated the fifth industry is excluded.

The estimates of the consumption and market risks associated with the various portfolios are systematically positive, and they are often statistically different from zero. However, the downside consumption and market risks are generally about the same size of their upside counterparts, and are never statistically different across regimes.

Moreover, the estimates of the responses to consumption and market risks in the unfavorable state are always positive, but are never significant. In contrast, the responses to consumption and market risks in the favorable regime are systematically negative, and are sometimes significant. Finally, only the responses to consumption risks for the Manufacturing-Energy-Utilities and High-Tech industries are statistically different across regimes. 
Importantly, the extensions presented above reveal that the rich relations between equity premia and downside consumption risks are central for understanding the behavior of excess returns across the various portfolios. Specifically, the responses to downside consumption risks are almost always significant, and, in comparison, the responses to upside consumption risks and to market risks in the unfavorable and favorable states are much less often statistically different from zero. Furthermore, the compensations to downside consumption risks are most of the time statistically larger than the responses to upside consumption risks, and are much larger for firms having smaller sizes and facing more financial distresses. This suggests, among other things, that substantial compensations may be requested by investors to cover for the fact that small firms are less well collateralized than large firms, and thus, are more likely to be subject to binding credit constraints (e.g. Gertler and Gilchrist 1994). It is interesting to note, however, that the pronounced heterogeneity in the prices of downside consumption risks across portfolios occur even if the levels of these risks, although being often significant, are not much larger for smaller firms, for more financially fragile firms, or for specific industries.

\section{Conclusion}

In this paper, we have investigated the empirical relations between equity premia and state-dependent consumption and market risks. These relations are derived from a flexible specification of the CCAPM. To obtain this specification, we preserve the conventional fundamental economic assumptions, but we relax the usual auxiliary distributional assumptions stipulating that the variables of interest are jointly governed by a normal distribution. Instead, we use a flexible, yet tractable, mixture of truncated joint normal distributions which admits the existence of two distinct regimes. This distribution is motivated by the overwhelming empirical evidence against the validity of the normal distribution. Also, the mixture distribution offers the considerable advantage of generating rich patterns of de- 
pendence across states. Such dependence allows for the existence of downside and upside risks.

Empirically, the estimates of the responses of expected equity returns to consumption and market risks in each state are computed from the estimates of the parameters involved in the CCAPM with mixture distribution, which are obtained by applying the maximumlikelihood method on monthly post-1960 U.S. data. Our basic results, focusing exclusively on the market return, indicate that the estimates of the responses to consumption and market risks are always significant, such that both sources of risks are priced in each state. Also, the responses to downside consumption and market risks are statistically larger than the responses associated with the upside counterparts, so that the responses to both consumption and market risks are state dependent. Furthermore, the extensions, incorporating various portfolio returns, reveal that the responses to downside consumption risks are most often significant, in comparison to the responses to other sources of risks. In addition, the responses to downside consumption risks are most of the time statistically larger than the responses to upside consumption risks, and are much larger for firms having smaller sizes and facing more financial distresses. 


\section{Appendix}

\section{A. Moment Generating Function}

The moment generating function is obtained by solving:

$$
\begin{aligned}
M & =\int_{-\infty}^{+\infty} \cdots \int_{-\infty}^{+\infty} \exp \left(\boldsymbol{\Gamma}^{\prime} \mathbf{X}_{t+1}\right) f\left(\mathbf{X}_{t+1} \mid \boldsymbol{\Omega}_{t} ; \boldsymbol{\Theta}\right) \prod_{i=1}^{n+2} d x_{i, t+1} \\
& =\pi_{1} M_{1}+\pi_{2} M_{2}
\end{aligned}
$$

where

$$
\begin{aligned}
& M_{1}=\frac{1}{(2 \pi)^{\frac{n+2}{2}}\left|\boldsymbol{\Sigma}_{1}\right|^{\frac{1}{2}} k_{1}} \int_{-\infty}^{\tau} \ldots \int_{-\infty}^{+\infty} \exp \left(\boldsymbol{\Gamma}^{\prime} \mathbf{X}_{t+1}\right) \exp \left[-\frac{1}{2}\left(\mathbf{X}_{t+1}-\boldsymbol{\Lambda}\right)^{\prime} \boldsymbol{\Sigma}_{1}^{-1}\left(\mathbf{X}_{t+1}-\boldsymbol{\Lambda}\right)\right] \prod_{i=1}^{n+2} d x_{i, t+1}, \\
& M_{2}=\frac{1}{(2 \pi)^{\frac{n+2}{2}}\left|\boldsymbol{\Sigma}_{2}\right|^{\frac{1}{2}} k_{2}} \int_{\tau}^{+\infty} \cdots \int_{-\infty}^{+\infty} \exp \left(\boldsymbol{\Gamma}^{\prime} \mathbf{X}_{t+1}\right) \exp \left[-\frac{1}{2}\left(\mathbf{X}_{t+1}-\boldsymbol{\Lambda}\right)^{\prime} \boldsymbol{\Sigma}_{2}^{-1}\left(\mathbf{X}_{t+1}-\boldsymbol{\Lambda}\right)\right] \prod_{i=1}^{n+2} d x_{i, t+1} .
\end{aligned}
$$

The vector $\boldsymbol{\Gamma}=\left[\gamma_{i}\right]$ (with $i=1, \ldots, n, c, m$ ) contains real values. In equation (A.1), $M$ is evaluated from the unconditional density function (1). Expression (A.2) decomposes $M$ in terms, $\pi_{s} M_{s}$ (with $s=1,2$ ), associated with each state, where the terms are evaluated from the joint density functions, $\pi_{s} f\left(\mathbf{X}_{t+1} \mid s_{t+1}=s, \boldsymbol{\Omega}_{t} ; \boldsymbol{\Theta}\right)$. In equations (A.3) and (A.4), $M_{s}$ is evaluated from the conditional density function (2) associated with state $s$, where the indicator variable is $I_{s, t+1}=1$ because the integrals are bounded such that state $s$ holds.

Partitionning the matrices in (A.3) yields:

$$
\begin{aligned}
M_{1} & =\frac{1}{(2 \pi)^{\frac{n+2}{2}}\left|\boldsymbol{\Sigma}_{1}\right|^{\frac{1}{2}} k_{1}} \exp \left(\boldsymbol{\Gamma}^{\prime} \boldsymbol{\Lambda}\right) \int_{-\infty}^{\delta} \ldots \int_{-\infty}^{+\infty} \exp \left(\boldsymbol{\Gamma}_{o}^{\prime} \mathbf{Y}_{o, t+1}+\gamma_{m} y_{m, t+1}\right) \\
& \exp \left[-\frac{1}{2}\left(\mathbf{Y}_{o, t+1}^{\prime} \boldsymbol{\Sigma}_{1}^{*} \mathbf{Y}_{o, t+1}-2 \mathbf{Y}_{o, t+1}^{\prime} \boldsymbol{\Sigma}_{1}^{*} \boldsymbol{\Sigma}_{1, o m} \frac{y_{m, t}}{\sigma_{1, m m}}+\left(\sigma_{1, m m}+\boldsymbol{\Sigma}_{1, o m}^{\prime} \boldsymbol{\Sigma}_{1}^{*} \boldsymbol{\Sigma}_{1, o m}\right) \frac{y_{m, t}^{2}}{\sigma_{1, m m}^{2}}\right)\right] \prod_{i=1}^{n+2} d y_{i, t+1} \cdot(
\end{aligned}
$$

Here, $\mathbf{Y}_{t+1}=\left(\mathbf{X}_{t+1}-\mathbf{\Lambda}\right)=\left(\begin{array}{ll}\mathbf{Y}_{o, t+1}^{\prime} & y_{m, t+1}\end{array}\right)^{\prime}=\left[y_{i, t+1}\right]$, where the scalar $y_{m, t+1}$ is the deviation of the market return relative to its mode and the vector $\mathbf{Y}_{o, t+1}$ includes the deviations of the other variables to their modes. Likewise, $\boldsymbol{\Gamma}=\left(\begin{array}{ll}\boldsymbol{\Gamma}_{o}^{\prime} & \gamma_{m}\end{array}\right)^{\prime}, \boldsymbol{\Sigma}_{1}=\left(\begin{array}{cc}\boldsymbol{\Sigma}_{1, o o} & \boldsymbol{\Sigma}_{1, o m} \\ \boldsymbol{\Sigma}_{1, o m}^{\prime} & \sigma_{1, m m}\end{array}\right)^{\prime}$, and $\boldsymbol{\Sigma}_{1}^{*}=\left(\boldsymbol{\Sigma}_{1, o o}-\frac{1}{\sigma_{1, m m}} \boldsymbol{\Sigma}_{1, o m} \boldsymbol{\Sigma}_{1, o m}^{\prime}\right)^{-1}$.

Transforming the variables in (A.5) produces:

$$
\begin{aligned}
M_{1}= & \frac{1}{(2 \pi)^{\frac{n+2}{2}} k_{1}} \exp \left(\boldsymbol{\Gamma}^{\prime} \boldsymbol{\Lambda}\right) \int_{-\infty}^{\delta / \sqrt{\sigma_{1, m m}}} \exp \left[\boldsymbol{\Gamma}^{\prime} \mathbf{\Psi}_{1} z_{m, t}-\frac{1}{2} z_{m, t}^{2}\right] d z_{m, t+1} \\
& \int_{-\infty}^{+\infty} \cdots \int_{-\infty}^{+\infty} \exp \left[\boldsymbol{\Gamma}_{o}^{\prime} \boldsymbol{\Sigma}_{1}^{*^{-1 / 2}} \mathbf{Z}_{o, t+1}-\frac{1}{2} \mathbf{Z}_{o, t+1}^{\prime} \mathbf{Z}_{o, t+1}\right] \prod_{i=1}^{n+1} d z_{i, t+1}
\end{aligned}
$$

The transformed variables are $z_{m, t+1}=\frac{y_{m, t+1}}{\sqrt{\sigma_{1, m m}}}$ and $\mathbf{Z}_{o, t+1}=\boldsymbol{\Sigma}_{1}^{* \frac{1}{2}}\left(\mathbf{Y}_{o, t+1}-\frac{1}{\sigma_{1, m m}} \boldsymbol{\Sigma}_{1, o m} y_{m, t+1}\right)$. The determinant of the Jacobian matrix is $\left|\boldsymbol{\Sigma}_{1}\right|^{\frac{1}{2}}=\sigma_{1, m m}^{\frac{1}{2}}\left|\boldsymbol{\Sigma}_{1}^{*}\right|^{-\frac{1}{2}}$. Note also that $\boldsymbol{\Gamma}^{\prime} \boldsymbol{\Psi}_{1}=\left(\frac{1}{\sqrt{\sigma_{1, m m}}} \boldsymbol{\Gamma}_{o}^{\prime} \boldsymbol{\Sigma}_{1, o m}+\sqrt{\sigma_{1, m m}} \gamma_{m}\right)$. 
Centering the variables in (A.6) implies:

$$
\begin{aligned}
M_{1}= & \frac{1}{k_{1}} \exp \left(\boldsymbol{\Gamma}^{\prime} \boldsymbol{\Lambda}+\frac{\boldsymbol{\Gamma}^{\prime} \boldsymbol{\Sigma}_{1} \boldsymbol{\Gamma}}{2}\right) \int_{-\infty}^{\delta / \sqrt{\sigma_{1, m m}}-\boldsymbol{\Gamma}^{\prime} \mathbf{\Psi}_{1}} \frac{1}{\sqrt{2 \pi}} \exp \left(-\frac{1}{2} z_{m, t+1}^{*^{2}}\right) d z_{m, t+1}^{*} \\
& \int_{-\infty}^{+\infty} \ldots \int_{-\infty}^{+\infty} \frac{1}{(2 \pi)^{\frac{n+1}{2}}} \exp \left(-\frac{1}{2} \mathbf{Z}_{t+1}^{*} \mathbf{Z}_{t+1}^{*}\right) \prod_{i=1}^{n+1} d z_{i, t+1}^{*}
\end{aligned}
$$

or

$$
M_{1}=\frac{\kappa_{1}}{k_{1}} \exp \left(\boldsymbol{\Gamma}^{\prime} \boldsymbol{\Lambda}+\frac{\boldsymbol{\Gamma}^{\prime} \boldsymbol{\Sigma}_{1} \boldsymbol{\Gamma}}{2}\right)
$$

The centered variables are $z_{m, t+1}^{*}=\left(z_{m, t+1}-\boldsymbol{\Psi}_{1}^{\prime} \boldsymbol{\Gamma}\right)$ and $\mathbf{Z}_{o, t+1}^{*}=\left(\mathbf{Z}_{o, t+1}-\boldsymbol{\Sigma}_{1}^{*-\frac{1}{2}} \boldsymbol{\Gamma}_{o}\right)$. Note also that $\boldsymbol{\Gamma}^{\prime} \boldsymbol{\Sigma}_{1} \boldsymbol{\Gamma}=$ $\boldsymbol{\Gamma}^{\prime} \boldsymbol{\Psi}_{1} \boldsymbol{\Psi}_{1}^{\prime} \boldsymbol{\Gamma}+\boldsymbol{\Gamma}_{o}^{\prime} \boldsymbol{\Sigma}_{1}^{*-1} \boldsymbol{\Gamma}_{0}$. In addition, $\kappa_{1}=F\left[\frac{\delta}{\sqrt{\sigma_{1, m m}}}-\boldsymbol{\Gamma}^{\prime} \boldsymbol{\Psi}_{1}\right]=\operatorname{Pr}\left[z_{m, t+1}^{*} \leq \frac{\delta}{\sqrt{\sigma_{1, m m}}}-\boldsymbol{\Gamma}^{\prime} \boldsymbol{\Psi}_{1}\right]$ and $1=\operatorname{Pr}\left[z_{i, t+1}^{*} \leq\right.$ $+\infty]$ (with $i \neq m$ ) correspond to the cumulative functions of univariate normal distributions.

Similarly, it can be shown that:

$$
M_{2}=\frac{\kappa_{2}}{k_{2}} \exp \left(\boldsymbol{\Gamma}^{\prime} \boldsymbol{\Lambda}+\frac{\boldsymbol{\Gamma}^{\prime} \boldsymbol{\Sigma}_{2} \boldsymbol{\Gamma}}{2}\right)
$$

where $\kappa_{2}=\left[1-F\left[\frac{\delta}{\sqrt{\sigma_{2, m m}}}-\Gamma^{\prime} \Psi_{2}\right]\right]$.

Using (A.2), (A.8), and (A.9) yields the moment generating function:

$$
M=\pi_{1} \frac{\kappa_{1}}{k_{1}} \exp \left(\boldsymbol{\Gamma}^{\prime} \boldsymbol{\Lambda}+\frac{\boldsymbol{\Gamma}^{\prime} \boldsymbol{\Sigma}_{1} \boldsymbol{\Gamma}}{2}\right)+\pi_{2} \frac{\kappa_{2}}{k_{2}} \exp \left(\boldsymbol{\Gamma}^{\prime} \boldsymbol{\Lambda}+\frac{\boldsymbol{\Gamma}^{\prime} \boldsymbol{\Sigma}_{2} \boldsymbol{\Gamma}}{2}\right),
$$

where $\left.M\right|_{\boldsymbol{\Gamma}=\mathbf{0}}=1$.

\section{B. Moments and Semi-Moments}

The first and second moments and semi-moments are obtained by solving:

$$
\begin{aligned}
E\left[\mathbf{X}_{t+1} \mid \boldsymbol{\Omega}_{t}\right] & =\left.\pi_{1} \frac{\partial M_{1}}{\partial \boldsymbol{\Gamma}}\right|_{\boldsymbol{\Gamma}=0}+\left.\pi_{2} \frac{\partial M_{2}}{\partial \boldsymbol{\Gamma}}\right|_{\boldsymbol{\Gamma}=0}, \\
E\left[\mathbf{X}_{t+1} \mid s_{t+1}, \Omega_{t}\right] & =\left.\frac{\partial M_{s}}{\partial \boldsymbol{\Gamma}}\right|_{\boldsymbol{\Gamma}=0},
\end{aligned}
$$

and

$$
\begin{aligned}
E\left[\mathbf{X}_{t+1} \mathbf{X}_{t+1}^{\prime} \mid \boldsymbol{\Omega}_{t}\right] & =\left.\pi_{1} \frac{\partial^{2} M_{1}}{\partial \boldsymbol{\Gamma} \partial \boldsymbol{\Gamma}^{\prime}}\right|_{\boldsymbol{\Gamma}=0}+\left.\pi_{2} \frac{\partial^{2} M_{2}}{\partial \boldsymbol{\Gamma} \partial \boldsymbol{\Gamma}^{\prime}}\right|_{\boldsymbol{\Gamma}=0}, \\
E\left[\mathbf{X}_{t+1} \mathbf{X}_{t+1}^{\prime} \mid s_{t+1}, \Omega_{t}\right] & =\left.\frac{\partial^{2} M_{s}}{\partial \boldsymbol{\Gamma} \partial \boldsymbol{\Gamma}^{\prime}}\right|_{\boldsymbol{\Gamma}=0},
\end{aligned}
$$


with

$$
\begin{aligned}
\mathbf{\Upsilon} & =E\left[\mathbf{X}_{t+1} \mathbf{X}_{t+1}^{\prime} \mid \Omega_{t}\right]-E\left[\mathbf{X}_{t+1} \mid \Omega_{t}\right] E\left[\mathbf{X}_{t+1} \mid \Omega_{t}\right]^{\prime} \\
\mathbf{\Upsilon}_{s} & =E\left[\mathbf{X}_{t+1} \mathbf{X}_{t+1}^{\prime} \mid s_{t+1}, \Omega_{t}\right]-E\left[\mathbf{X}_{t+1} \mid s_{t+1}, \Omega_{t}\right] E\left[\mathbf{X}_{t+1} \mid s_{t+1}, \Omega_{t}\right]^{\prime}
\end{aligned}
$$

and $s=1,2$.

Using (A.8) and (A.9) yields:

$$
\begin{aligned}
\frac{\partial M_{s}}{\partial \boldsymbol{\Gamma}} & =M_{s}\left\{\boldsymbol{\Lambda}+\boldsymbol{\Sigma}_{s} \boldsymbol{\Gamma}+\frac{(-1)^{s}}{\sqrt{2 \pi} \kappa_{s}} \exp \left[-\frac{1}{2}\left(\frac{\delta}{\sqrt{\sigma_{s, m m}}}-\boldsymbol{\Gamma}^{\prime} \boldsymbol{\Psi}_{s}\right)^{2}\right] \boldsymbol{\Psi}_{s}\right\} \\
\frac{\partial^{2} M_{s}}{\partial \boldsymbol{\Gamma} \partial \boldsymbol{\Gamma}^{\prime}} & =\left\{\boldsymbol{\Lambda}+\boldsymbol{\Sigma}_{s} \boldsymbol{\Gamma}+\frac{(-1)^{s}}{\sqrt{2 \pi} \kappa_{s}} \exp \left[-\frac{1}{2}\left(\frac{\delta}{\sqrt{\sigma_{s, m m}}}-\boldsymbol{\Gamma}^{\prime} \boldsymbol{\Psi}_{s}\right)^{2}\right] \boldsymbol{\Psi}_{s}\right\}\left(\frac{\partial M_{s}}{\partial \boldsymbol{\Gamma}}\right)^{\prime}+M_{s}\left\{\boldsymbol{\Sigma}_{s}-\exp \left[-\frac{1}{2}\left(\frac{\delta}{\sqrt{\sigma_{s, m m}}}-\boldsymbol{\Gamma}^{\prime} \boldsymbol{\Psi}_{s}\right)^{2}\right]\right. \\
& \left.\frac{1}{\sqrt{2 \pi} \kappa_{s}}\left[\frac{1}{\sqrt{2 \pi} \kappa_{s}} \exp \left[-\frac{1}{2}\left(\frac{\delta}{\sqrt{\sigma_{s, m m}}}-\boldsymbol{\Gamma}^{\prime} \boldsymbol{\Psi}_{s}\right)^{2}\right]-(-1)^{s}\left(\frac{\delta}{\sqrt{\sigma_{s, m m}}}-\boldsymbol{\Gamma}^{\prime} \boldsymbol{\Psi}_{s}\right)\right] \boldsymbol{\Psi}_{s} \boldsymbol{\Psi}_{s}^{\prime}\right\} .
\end{aligned}
$$

Evaluating (B.7) and (B.8) at $\boldsymbol{\Gamma}=\mathbf{0}$ produces:

$$
\begin{aligned}
\left.\frac{\partial M_{s}}{\partial \boldsymbol{\Gamma}}\right|_{\boldsymbol{\Gamma}=0} & =\boldsymbol{\Lambda}+(-1)^{s} \frac{\eta_{s}}{\sqrt{2 \pi}} \boldsymbol{\Psi}_{s} \\
\left.\frac{\partial^{2} M_{s}}{\partial \boldsymbol{\Gamma} \partial \boldsymbol{\Gamma}^{\prime}}\right|_{\boldsymbol{\Gamma}=0} & =\left[\boldsymbol{\Sigma}_{s}-\frac{\eta_{s}}{\sqrt{2 \pi}}\left[\frac{\eta_{s}}{\sqrt{2 \pi}}-(-1)^{s} \frac{\delta}{\sqrt{\sigma_{s, m m}}}\right] \boldsymbol{\Psi}_{s} \boldsymbol{\Psi}_{s}^{\prime}\right]+\left[\boldsymbol{\Lambda}+(-1)^{s} \frac{\eta_{s}}{\sqrt{2 \pi}} \boldsymbol{\Psi}_{s}\right]\left[\boldsymbol{\Lambda}+(-1)^{s} \frac{\eta_{s}}{\sqrt{2 \pi}} \boldsymbol{\Psi}_{s}\right]^{\prime}(B . B .
\end{aligned}
$$

Substituting (B.9) and (B.10) in (B.1), (B.3), and (B.5) yields the first and second moments (4) and (5). Also, substituting (B.9) and (B.10) in (B.2), (B.4), and (B.6) produces the first and second semi-moments (6) and (7).

\section{Excess Returns}

The expected excess return for the risky asset $i$ is obtained by solving:

$$
E\left[x_{i, t+1}^{e} \mid \boldsymbol{\Omega}_{t}\right]=E\left[x_{i, t+1} \mid \boldsymbol{\Omega}_{t}\right]-x_{f, t+1} .
$$

The expected return for the risky asset is derived as follows. First, the Euler equation (8) for asset $i$ is written as:

$$
1=\beta E \exp \left[\left(x_{i, t+1}-\alpha x_{c, t+1}\right) \mid \boldsymbol{\Omega}_{t}\right] .
$$

Second, the expectation in (C.2) is constructed from the moment generating function (A.10), evaluated at $\boldsymbol{\Gamma}=$ $\left(\mathbf{e}_{i}-\alpha \mathbf{e}_{n+1}\right)$ where $\mathbf{e}_{k}$ is a vector containing the value one in the $k$ th position and zeros elsewhere. This yields:

$$
1=\beta \exp \left(\lambda_{i}-\alpha \lambda_{c}\right)\left[\pi_{1} \phi_{1, i} \exp \left(\frac{\sigma_{1, i i}}{2}+\alpha^{2} \frac{\sigma_{1, c c}}{2}-\alpha \sigma_{1, i c}\right)+\pi_{2} \phi_{2, i} \exp \left(\frac{\sigma_{2, i i}}{2}+\alpha^{2} \frac{\sigma_{2, c c}}{2}-\alpha \sigma_{2, i c}\right)\right] .
$$


Third, $\lambda_{i}$ in (C.3) is substituted out from (4) and logarithms are taken to produce:

$$
\begin{aligned}
E\left[x_{i, t+1} \mid \boldsymbol{\Omega}_{t}\right] & =-\log \beta+\alpha \lambda_{c}-\frac{1}{\sqrt{2 \pi}}\left[\pi_{1} \eta_{1} \frac{\sigma_{1, i m}}{\sqrt{\sigma_{1, m m}}}-\pi_{2} \eta_{2} \frac{\sigma_{2, i m}}{\sqrt{\sigma_{2, m m}}}\right] \\
& -\log \left[\pi_{1} \phi_{1, i} \exp \left(\frac{\sigma_{1, i i}}{2}+\alpha^{2} \frac{\sigma_{1, c c}}{2}-\alpha \sigma_{1, i c}\right)+\pi_{2} \phi_{2, i} \exp \left(\frac{\sigma_{2, i i}}{2}+\alpha^{2} \frac{\sigma_{2, c c}}{2}-\alpha \sigma_{2, i c}\right)\right] .
\end{aligned}
$$

Also, the riskfree rate is derived in a similar way, but this time the moment generating function (A.10) is evaluated at $\boldsymbol{\Gamma}=-\alpha \mathbf{e}_{n+1}$. This yields:

$$
x_{f, t+1}=-\log \beta+\alpha \lambda_{c}-\log \left[\pi_{1} \phi_{1, f} \exp \left(\alpha^{2} \frac{\sigma_{1, c c}}{2}\right)+\pi_{2} \phi_{2, f} \exp \left(\alpha^{2} \frac{\sigma_{2, c c}}{2}\right)\right] .
$$

Using (C.1), (C.4), and (C.5) leads to the equity premium (9). 


\section{References}

Ang, A., and J. Chen (2002) "Asymmetric Correlations of Equity Portfolios," Journal of Financial Economics 63, pp. 443-494.

Ang, A., J. Chen, and Y. Xing (2006) "Downside Risk," Review of Financial Studies 19, pp. 1191-1239.

Bakshi, G.S., and Z. Chen (1996) "The Spirit of Capitalism and Stock-Market Prices," American Economic Review 86, pp. 133-157.

Balke, N.S., and T.B. Fomby (1994) "Large Shocks, Small Shocks, and Economic Fluctuations: Outliers in Macroeconomic Time Series" Journal of Applied Econometrics 9, pp. 181-200.

Ball, R., and S.P. Kothari (1989) "Nonstationary Expected Returns: Implications for Tests of Market Efficiency and Serial Correlation in Returns," Journal of Financial Economics 25, pp. 51-74.

Bawa, V.S., and E.B. Linderberg (1977) "Capital Market Equilibrium in a Mean-Lower Partial Moment Framework," Journal of Financial Economics 5, pp. 189-200.

Bekaert, G., and G. Wu (2000) "Asymmetric Volatility and Risk in Equity Markets" Review of Financial Studies 13, pp. 1-42.

Braun, P.A., D.N. Nelson, and A.M. Sunier (1995) "Good News, Bad News, Volatility and Betas." Journal of Finance 50, pp. 1575-1603.

Butler, K.C., and D.C. Joaquin (2002) "Are the Gains from International Portfolio Diversification Exaggerated? The Influence of Downside Risk in Bear Markets," Journal of International Money and Finance 21, pp. 981-1011.

Campbell, J.Y., and J.H. Cochrane (1999) "By Force of Habit: A Consumption-Based Explanation of Aggregate Stock Market Behavior," Journal of Political Economy 107, pp. 205-251.

Cecchetti, S.G., P.-S. Lam, and N.C. Mark (1993) "The Equity Premium and the Risk-Free Rate: Matching the Moments," Journal of Monetary Economics 31, pp. 21-45.

Cecchetti, S.G., P.-S. Lam, and N.C. Mark (1990) "Mean Reversion in Equilibrium Asset Prices," American Economic Review 80, pp. 398-418. 
Conrad, J., M. Gultekin, and G. Kaul (1991) "Asymmetric Predictability of Conditional Variances," Review of Financial Studies 4, pp. 597-622.

Constantinides, G.M. (1990) "Habit Formation: A Resolution of the Equity Premium Puzzle," Journal of Political Economy 98, pp. 519-543.

Epstein, L.G., and S.E. Zin (1991) "Substitution, Risk Aversion and the Temporal Behaviour of Consumption and Asset Returns: An Empirical Analysis," Journal of Political Economy 99, pp. 263-286.

Gordon, S., and P. St-Amour (2000) "A Preference Regime Model of Bull and Bear Markets," American Economic Review 90, pp. 1019-1033.

Gul, F. (1991) "A Theory of Disappointment Aversion," Econometrica 59, pp. 667-686.

Hamilton, J.D. (1989) "A New Approach to the Economic Analysis of Nonstationary Time Series and the Business Cycle," Econometrica 57, pp. 357-384.

Hansen, L.P., and K.J. Singleton (1983) "Stochastic Consumption, Risk-Aversion, and the Temporal Behavior of Asset Returns," Journal of Political Economy 91 pp. 249-265.

Hansen, L.P., and K.J. Singleton (1982) "Generalized Instrumental Variables Estimation of Nonlinear Rational Expectations Models," Econometrica 50, pp. 1269-1286.

John, S. (1982) "The Three-Parameter Two-Piece Normal Family of Distributions and its Fitting," Communication in Statistics: Theory and Methods 11, pp. 879-885.

Kandel, S., and R.F. Stambaugh (1990) "Expectations and Volatility of Consumption and Asset Returns," Review of Financial Studies 3, pp. 207-232.

Kroner, K.F., and V.K. Ng (1998) "Modeling Asymmetric Comovements of Asset Returns," Review of Financial Studies 11, pp. 817-844.

Longin, F., and B. Solnik (2001) "Extreme Correlation of International Equity Markets," Journal of Finance 56, pp. 649-676.

Markowitz, H. (1959) Porfolio Selection, John Wiley \& Sons, New York, NY.

Normandin, M., and P. St-Amour (1998) "Substitution, Risk Aversion, Taste Shocks and Equity Premia," Journal of Applied Econometrics 13, pp. 265-281. 
Table 1. Basic Results

\begin{tabular}{|c|c|c|c|c|}
\hline & \multicolumn{3}{|c|}{ Mixture } & \multirow[t]{3}{*}{ Normal } \\
\hline & \multicolumn{3}{|c|}{ A. Estimates } & \\
\hline & $\begin{array}{c}\text { Downside } \\
\quad(s=1)\end{array}$ & $\begin{array}{l}\text { Upside } \\
(s=2)\end{array}$ & Test & \\
\hline \multicolumn{5}{|c|}{ Consumption Risk } \\
\hline$v_{s, m c}$ & $\begin{array}{c}0.0082 \\
(0.0022)\end{array}$ & $\begin{array}{c}0.0030 \\
(0.0027)\end{array}$ & {$[0.0269]$} & $\begin{array}{r}0.0034 \\
(0.0010)\end{array}$ \\
\hline$\rho_{s, m c}$ & $\begin{array}{r}12.762 \\
(0.7783)\end{array}$ & $\begin{array}{c}5.9207 \\
(0.3438)\end{array}$ & {$[0.0000]$} & $\begin{array}{r}57.230 \\
(27.421)\end{array}$ \\
\hline \multicolumn{5}{|l|}{ Market Risk } \\
\hline$v_{s, m m}$ & $\begin{array}{c}0.5248 \\
(0.0597)\end{array}$ & $\begin{array}{c}0.3740 \\
(0.0394)\end{array}$ & {$[0.0087]$} & $\begin{array}{r}0.2715 \\
(0.0218)\end{array}$ \\
\hline$\rho_{s, m m}$ & $\begin{array}{c}0.6357 \\
(0.0573)\end{array}$ & $\begin{array}{l}-0.3876 \\
(0.0859)\end{array}$ & {$[0.0000]$} & $\begin{array}{l}0.0000 \\
-\end{array}$ \\
\hline \multicolumn{5}{|c|}{ Other Parameters } \\
\hline$v_{s, c c}$ & $\begin{array}{c}0.0019 \\
(0.0001)\end{array}$ & $\begin{array}{c}0.0011 \\
(0.0002)\end{array}$ & {$[0.0013]$} & $\begin{array}{r}0.0018 \\
(0.0001)\end{array}$ \\
\hline$\delta$ & $\begin{array}{c}0.4400 \\
(0.0458)\end{array}$ & & & $\begin{array}{c}0.0000 \\
-\end{array}$ \\
\hline$\alpha$ & $\begin{array}{r}36.003 \\
(5.4325)\end{array}$ & & & $\begin{array}{r}57.230 \\
(27.421)\end{array}$ \\
\hline$\lambda_{c}$ & $\begin{array}{c}0.0232 \\
(0.0020)\end{array}$ & & & $\begin{array}{r}0.0214 \\
(0.0015)\end{array}$ \\
\hline \multicolumn{5}{|c|}{ B. Information Criteria and Statistical Tests } \\
\hline $2(\log L)$ & 1156.30 & & {$[0.0000]$} & 1129.92 \\
\hline$A I C$ & 1138.30 & & & 1119.92 \\
\hline$B I C$ & 1099.10 & & & 1098.14 \\
\hline
\end{tabular}

Notes: Panel A. Entries are the estimates for the bivariate specifications involving the CCAPM with mixture distribution (Mixture) and normal distribution (Normal). Numbers in parentheses are the standard errors of the estimates. Numbers in brackets are the $p$-values associated with the $\chi^{2}$-distributed Wald test that the risks or responses are the same across states. Panel $B$. Entries are two times the $\log$-likelihood value $2(\log L)$, the Akaike information criterion $(A I C)$, and Bayesian information criterion $(B I C): A I C=2(\log L)-2 p$ and $B I C=2(\log L)-(\log T) p$, where $p$ is the number of parameters, and $T$ is the sample size. The number in brackets is the $p$ value associated with the $\chi^{2}$-distributed likelihood-ratio test comparing the specifications Mixture and Normal. 
Table 2. Extensions: Size Portfolios

\begin{tabular}{|c|c|c|c|c|c|c|c|}
\hline \multicolumn{8}{|c|}{ A. Consumption Risk } \\
\hline & $\begin{array}{c}\text { Downside } \\
\quad(s=1)\end{array}$ & $\begin{array}{l}\text { Upside } \\
(s=2)\end{array}$ & Test & & $\begin{array}{c}\text { Downside } \\
\quad(s=1)\end{array}$ & $\begin{array}{l}\text { Upside } \\
(s=2)\end{array}$ & Test \\
\hline$v_{s, 1 c}$ & $\begin{array}{c}0.0199 \\
(0.0037)\end{array}$ & $\begin{array}{c}0.0101 \\
(0.0042)\end{array}$ & {$[0.0213]$} & $\rho_{s, 1 c}$ & $\begin{array}{r}31.6378 \\
(19.165)\end{array}$ & $\begin{array}{c}-6.31707 \\
(3.3690)\end{array}$ & {$[0.3066]$} \\
\hline$v_{s, 2 c}$ & $\begin{array}{c}0.0174 \\
(0.0036)\end{array}$ & $\begin{array}{c}0.0083 \\
(0.0039)\end{array}$ & {$[0.0215]$} & $\rho_{s, 2 c}$ & $\begin{array}{c}30.050 \\
(17.212)\end{array}$ & $\begin{array}{l}-4.2134 \\
(2.0061)\end{array}$ & {$[0.0649]$} \\
\hline$v_{s, 3 c}$ & $\begin{array}{r}0.0154 \\
(0.0034)\end{array}$ & $\begin{array}{c}0.0079 \\
(0.0037)\end{array}$ & {$[0.0395]$} & $\rho_{s, 3 c}$ & $\begin{array}{c}18.392 \\
(10.147)\end{array}$ & $\begin{array}{c}8.7469 \\
(7.8325)\end{array}$ & {$[0.0747]$} \\
\hline$v_{s, 5 c}$ & $\begin{array}{r}0.0205 \\
(0.0036)\end{array}$ & $\begin{array}{c}0.0108 \\
(0.0040)\end{array}$ & {$[0.0212]$} & $\rho_{s, 5 c}$ & $\begin{array}{c}13.032 \\
(7.0981)\end{array}$ & $\begin{array}{l}-0.4009 \\
(1.5887)\end{array}$ & {$[0.0349]$} \\
\hline$v_{s, m c}$ & $\begin{array}{c}0.0133 \\
(0.0032)\end{array}$ & $\begin{array}{c}0.0058 \\
(0.0033)\end{array}$ & {$[0.0253]$} & $\rho_{s, m c}$ & $\begin{array}{c}32.417 \\
(18.447)\end{array}$ & $\begin{array}{l}-3.3727 \\
(1.0340)\end{array}$ & {$[0.0094]$} \\
\hline \multicolumn{8}{|c|}{ B. Market Risk } \\
\hline & $\begin{array}{c}\text { Downside } \\
\quad(s=1)\end{array}$ & $\begin{array}{l}\text { Upside } \\
(s=2)\end{array}$ & Test & & $\begin{array}{c}\text { Downside } \\
\quad(s=1)\end{array}$ & $\begin{array}{l}\text { Upside } \\
(s=2)\end{array}$ & Test \\
\hline$v_{s, 1 m}$ & $\begin{array}{c}0.5136 \\
(0.0437)\end{array}$ & $\begin{array}{c}0.6847 \\
(0.1412)\end{array}$ & {$[0.1430]$} & $\rho_{s, 1 m}$ & $\begin{array}{c}6.1625 \\
(5.9645)\end{array}$ & $\begin{array}{l}-4.1407 \\
(1.9830)\end{array}$ & {$[0.4868]$} \\
\hline$v_{s, 2 m}$ & $\begin{array}{r}0.4917 \\
(0.0406)\end{array}$ & $\begin{array}{c}0.6437 \\
(0.1303)\end{array}$ & {$[0.1485]$} & $\rho_{s, 2 m}$ & $\begin{array}{c}4.8823 \\
(5.0313)\end{array}$ & $\begin{array}{l}-3.7933 \\
(1.7903)\end{array}$ & {$[0.0953]$} \\
\hline$v_{s, 3 m}$ & $\begin{array}{c}0.4656 \\
(0.0385)\end{array}$ & $\begin{array}{c}0.6381 \\
(0.1260)\end{array}$ & {$[0.1099]$} & $\rho_{s, 3 m}$ & $\begin{array}{l}-10.545 \\
(6.4087)\end{array}$ & $\begin{array}{c}1.4437 \\
(2.6690)\end{array}$ & {$[0.0097]$} \\
\hline$v_{s, 5 m}$ & $\begin{array}{c}0.4820 \\
(0.0422)\end{array}$ & $\begin{array}{c}0.6212 \\
(0.1321)\end{array}$ & {$[0.1800]$} & $\rho_{s, 5 m}$ & $\begin{array}{c}5.6062 \\
(5.5499)\end{array}$ & $\begin{array}{l}-3.7227 \\
(1.7572)\end{array}$ & {$[0.1937]$} \\
\hline$v_{s, m m}$ & $\begin{array}{r}0.4372 \\
(0.0358)\end{array}$ & $\begin{array}{c}0.5733 \\
(0.1143)\end{array}$ & {$[0.1401]$} & $\rho_{s, m m}$ & $\begin{array}{c}5.1088 \\
(5.7240)\end{array}$ & $\begin{array}{l}-3.7232 \\
(1.1814)\end{array}$ & {$[0.4392]$} \\
\hline
\end{tabular}

Notes: Entries are the estimates for the multivariate specification involving the CCAPM with mixture distribution. Numbers in parentheses are the standard errors of the estimates. Numbers in brackets are the $p$-values associated with the $\chi^{2}$-distributed Wald test that the risks or responses are the same across states. The portfolios $i=1, \ldots, 5$ are sorted by size, where $i$ refers to the quintile. 


\section{Table 3. Extensions: Growth Portfolios}

\begin{tabular}{|c|c|c|c|c|c|c|c|}
\hline \multicolumn{8}{|c|}{ A. Consumption Risk } \\
\hline & $\begin{array}{c}\text { Downside } \\
\quad(s=1)\end{array}$ & $\begin{array}{l}\text { Upside } \\
(s=2)\end{array}$ & Test & & $\begin{array}{c}\text { Downside } \\
\quad(s=1)\end{array}$ & $\begin{array}{l}\text { Upside } \\
(s=2)\end{array}$ & Test \\
\hline$v_{s, 2 c}$ & $\begin{array}{c}0.0093 \\
(0.0031)\end{array}$ & $\begin{array}{c}0.0060 \\
(0.0041)\end{array}$ & {$[0.1967]$} & $\rho_{s, 2 c}$ & $\begin{array}{r}49.513 \\
(44.921)\end{array}$ & $\begin{array}{l}-2.2980 \\
(4.1053)\end{array}$ & {$[0.4656]$} \\
\hline$v_{s, 3 c}$ & $\begin{array}{r}0.0100 \\
(0.0029)\end{array}$ & $\begin{array}{c}0.0063 \\
(0.0038)\end{array}$ & {$[0.1557]$} & $\rho_{s, 3 c}$ & $\begin{array}{c}59.030 \\
(35.705)\end{array}$ & $\begin{array}{l}-4.6876 \\
(4.1546)\end{array}$ & [0.0849] \\
\hline$v_{s, 4 c}$ & $\begin{array}{r}0.0107 \\
(0.0030)\end{array}$ & $\begin{array}{c}0.0076 \\
(0.0042)\end{array}$ & {$[0.2239]$} & $\rho_{s, 4 c}$ & $\begin{array}{c}57.578 \\
(32.896)\end{array}$ & $\begin{array}{l}-2.4717 \\
(4.0767)\end{array}$ & {$[0.0706]$} \\
\hline$v_{s, 5 c}$ & $\begin{array}{c}0.0098 \\
(0.0036)\end{array}$ & $\begin{array}{c}0.0082 \\
(0.0051)\end{array}$ & {$[0.3685]$} & $\rho_{s, 5 c}$ & $\begin{array}{c}60.144 \\
(33.451)\end{array}$ & $\begin{array}{c}3.2972 \\
(6.9714)\end{array}$ & {$[0.0733]$} \\
\hline$v_{s, m c}$ & $\begin{array}{c}0.0098 \\
(0.0034)\end{array}$ & $\begin{array}{c}0.0065 \\
(0.0045)\end{array}$ & {$[0.2111]$} & $\rho_{s, m c}$ & $\begin{array}{c}65.811 \\
(59.413)\end{array}$ & $\begin{array}{l}-6.6255 \\
(4.2725)\end{array}$ & {$[0.2457]$} \\
\hline \multicolumn{8}{|c|}{ B. Market Risk } \\
\hline & $\begin{array}{c}\text { Downside } \\
\quad(s=1)\end{array}$ & $\begin{array}{l}\text { Upside } \\
(s=2)\end{array}$ & Test & & $\begin{array}{c}\text { Downside } \\
\quad(s=1)\end{array}$ & $\begin{array}{c}\text { Upside } \\
(s=2)\end{array}$ & Test \\
\hline$v_{s, 2 m}$ & $\begin{array}{c}0.3978 \\
(0.0426)\end{array}$ & $\begin{array}{c}0.4560 \\
(0.1597)\end{array}$ & {$[0.3624]$} & $\rho_{s, 2 m}$ & $\begin{array}{r}4.5813 \\
(7.7886)\end{array}$ & $\begin{array}{l}-3.0858 \\
(4.0063)\end{array}$ & {$[0.3932]$} \\
\hline$v_{s, 3 m}$ & $\begin{array}{c}0.3695 \\
(0.0370)\end{array}$ & $\begin{array}{c}0.4325 \\
(0.1497)\end{array}$ & {$[0.3403]$} & $\rho_{s, 3 m}$ & $\begin{array}{c}22.362 \\
(22.1307)\end{array}$ & $\begin{array}{l}-5.0691 \\
(4.2673)\end{array}$ & {$[0.1718]$} \\
\hline$v_{s, 4 m}$ & $\begin{array}{c}0.4102 \\
(0.0435)\end{array}$ & $\begin{array}{c}0.4700 \\
(0.1650)\end{array}$ & {$[0.3611]$} & $\rho_{s, 4 m}$ & $\begin{array}{c}15.714 \\
(16.642)\end{array}$ & $\begin{array}{l}-5.0603 \\
(4.2556)\end{array}$ & [0.2874] \\
\hline$v_{s, 5 m}$ & $\begin{array}{r}0.4835 \\
(0.0486)\end{array}$ & $\begin{array}{c}0.5553 \\
(0.1918)\end{array}$ & {$[0.3500]$} & $\rho_{s, 5 m}$ & $\begin{array}{l}-0.0798 \\
(4.8674)\end{array}$ & $\begin{array}{l}-1.5286 \\
(4.3044)\end{array}$ & {$[0.1448]$} \\
\hline$v_{s, m m}$ & $\begin{array}{c}0.4456 \\
(0.0450)\end{array}$ & $\begin{array}{c}0.5034 \\
(0.1764)\end{array}$ & {$[0.3686]$} & $\rho_{s, m m}$ & $\begin{array}{c}24.093 \\
(24.206)\end{array}$ & $\begin{array}{l}-5.8901 \\
(4.0044)\end{array}$ & {$[0.4700]$} \\
\hline
\end{tabular}

Notes: Entries are the estimates for the multivariate specification involving the CCAPM with mixture distribution. Numbers in parentheses are the standard errors of the estimates. Numbers in brackets are the $p$-values associated with the $\chi^{2}$-distributed Wald test that the risks or responses are the same across states. The portfolios $i=1, \ldots, 5$ are sorted by the book-to-market ratio, where $i$ refers to the quintile. 
Table 4. Extensions: Industry Portfolios

\begin{tabular}{|c|c|c|c|c|c|c|c|}
\hline \multicolumn{8}{|c|}{ A. Consumption Risk } \\
\hline & $\begin{array}{c}\text { Downside } \\
\quad(s=1)\end{array}$ & $\begin{array}{l}\text { Upside } \\
(s=2)\end{array}$ & Test & & $\begin{array}{c}\text { Downside } \\
\quad(s=1)\end{array}$ & $\begin{array}{l}\text { Upside } \\
(s=2)\end{array}$ & Test \\
\hline$v_{s, 1 c}$ & $\begin{array}{c}0.0054 \\
(0.0035)\end{array}$ & $\begin{array}{c}0.0079 \\
(0.0048)\end{array}$ & {$[0.2671]$} & $\rho_{s, 1 c}$ & $\begin{array}{c}47.644 \\
(57.3641)\end{array}$ & $\begin{array}{l}-11.134 \\
(5.4046)\end{array}$ & {$[0.4298]$} \\
\hline$v_{s, 2 c}$ & $\begin{array}{c}0.0049 \\
(0.0032)\end{array}$ & $\begin{array}{c}0.0072 \\
(0.0043)\end{array}$ & {$[0.2643]$} & $\rho_{s, 2 c}$ & $\begin{array}{c}32.735 \\
(42.903)\end{array}$ & $\begin{array}{c}-1.061 \\
(11.319)\end{array}$ & {$[0.0906]$} \\
\hline$v_{s, 3 c}$ & $\begin{array}{c}0.0062 \\
(0.0037)\end{array}$ & $\begin{array}{c}0.0098 \\
(0.0054)\end{array}$ & {$[0.2310]$} & $\rho_{s, 3 c}$ & $\begin{array}{c}40.769 \\
(50.718)\end{array}$ & $\begin{array}{c}-7.249 \\
(6.6677)\end{array}$ & {$[0.0600]$} \\
\hline$v_{s, 4 c}$ & $\begin{array}{c}0.0063 \\
(0.0028)\end{array}$ & $\begin{array}{c}0.0083 \\
(0.0045)\end{array}$ & {$[0.3058]$} & $\rho_{s, 4 c}$ & $\begin{array}{c}71.063 \\
(80.064)\end{array}$ & $\begin{array}{l}-18.680 \\
(8.9488)\end{array}$ & {$[0.1643]$} \\
\hline$v_{s, m c}$ & $\begin{array}{c}0.0050 \\
(0.0035)\end{array}$ & $\begin{array}{c}0.0052 \\
(0.0048)\end{array}$ & {$[0.2605]$} & $\rho_{s, m c}$ & $\begin{array}{c}62.689 \\
(72.488)\end{array}$ & $\begin{array}{l}-23.740 \\
(12.523)\end{array}$ & {$[0.2570]$} \\
\hline
\end{tabular}

B. Market Risk

\begin{tabular}{|c|c|c|c|c|c|c|c|}
\hline & $\begin{array}{c}\text { Downside } \\
(s=1)\end{array}$ & $\begin{array}{l}\text { Upside } \\
(s=2)\end{array}$ & Test & & $\begin{array}{c}\text { Downside } \\
(s=1)\end{array}$ & $\begin{array}{c}\text { Upside } \\
(s=2)\end{array}$ & Test \\
\hline$v_{s, 1 m}$ & $\begin{array}{c}0.4162 \\
(0.0439)\end{array}$ & $\begin{array}{c}0.0077 \\
(0.2025)\end{array}$ & {$[0.3334]$} & $\rho_{s, 1 m}$ & $\begin{array}{c}11.049 \\
(22.298)\end{array}$ & $\begin{array}{c}-9.4409 \\
(5.6971)\end{array}$ & {$[0.4196]$} \\
\hline$v_{s, 2 m}$ & $\begin{array}{c}0.3764 \\
(0.0406)\end{array}$ & $\begin{array}{c}0.4510 \\
(0.1835)\end{array}$ & {$[0.3370]$} & $\rho_{s, 2 m}$ & $\begin{array}{c}0.0286 \\
(12.146)\end{array}$ & $\begin{array}{l}-4.5368 \\
(8.4731)\end{array}$ & .1770 \\
\hline$v_{s, 3 m}$ & $\begin{array}{c}0.4912 \\
(0.0518)\end{array}$ & $\begin{array}{c}0.5630 \\
(0.2279)\end{array}$ & [0.3665] & $\rho_{s, 3 m}$ & $\begin{array}{c}6.1368 \\
(17.691)\end{array}$ & $\begin{array}{l}-7.7935 \\
(6.3560)\end{array}$ & {$[0.2825]$} \\
\hline$v_{s, 4 m}$ & $\begin{array}{c}0.3706 \\
(0.0458)\end{array}$ & $\begin{array}{c}0.4725 \\
(0.1958)\end{array}$ & {$[0.2969]$} & $\rho_{s, 4 m}$ & $\begin{array}{c}21.400 \\
(32.180)\end{array}$ & $\begin{array}{l}-13.852 \\
(5.9607)\end{array}$ & {$[0.4354$} \\
\hline ,mm & $\begin{array}{c}0.4458 \\
(0.0455)\end{array}$ & $\begin{array}{c}0.5000 \\
(0.2031)\end{array}$ & {$[0.3887]$} & $\rho_{s, m m}$ & $\begin{array}{c}23.758 \\
(34.918)\end{array}$ & $\begin{array}{l}-16.090 \\
(6.4549)\end{array}$ & {$[0.2830]$} \\
\hline
\end{tabular}

Notes: Entries are the estimates for the multivariate specification involving the CCAPM with mixture distribution. Numbers in parentheses are the standard errors of the estimates. Numbers in brackets are the $p$-values associated with the $\chi^{2}$-distributed Wald test that the risks or responses are the same across states. The portfolios $i=1, \ldots, 5$ are sorted by industries, where $i=1$ refers to Consumer, $i=2$ is Manufacturing, Energy, and Utilities, $i=3$ is High-Tech, $i=4$ is Health, and $i=5$ is Others. 


\section{Figure 1. Standardized Mixture Distribution}

Parametrization

$\boldsymbol{\Sigma}_{1}=\left(\begin{array}{cc}2 & 1.5 \\ 1.5 & 2\end{array}\right)$
$\boldsymbol{\Sigma}_{2}=\left(\begin{array}{cc}1 & 0.9 \\ 0.9 & 1\end{array}\right)$

$\boldsymbol{\Sigma}_{1}=\left(\begin{array}{cc}2 & -1.5 \\ -1.5 & 2\end{array}\right)$

$\boldsymbol{\Sigma}_{2}=\left(\begin{array}{cc}1 & -0.9 \\ -0.9 & 1\end{array}\right)$

$$
\begin{gathered}
\boldsymbol{\Sigma}_{1}=\left(\begin{array}{cc}
1.5 & -0.7 \\
-0.7 & 1.5
\end{array}\right) \\
\boldsymbol{\Sigma}_{2}=\left(\begin{array}{ll}
0.5 & 0.6 \\
0.6 & 0.4
\end{array}\right)
\end{gathered}
$$

$$
\begin{gathered}
\boldsymbol{\Sigma}_{1}=\left(\begin{array}{cc}
1.5 & 0.7 \\
0.7 & 1.5
\end{array}\right) \\
\boldsymbol{\Sigma}_{2}=\left(\begin{array}{cc}
0.5 & -0.6 \\
-0.6 & 0.4
\end{array}\right)
\end{gathered}
$$

Density Function
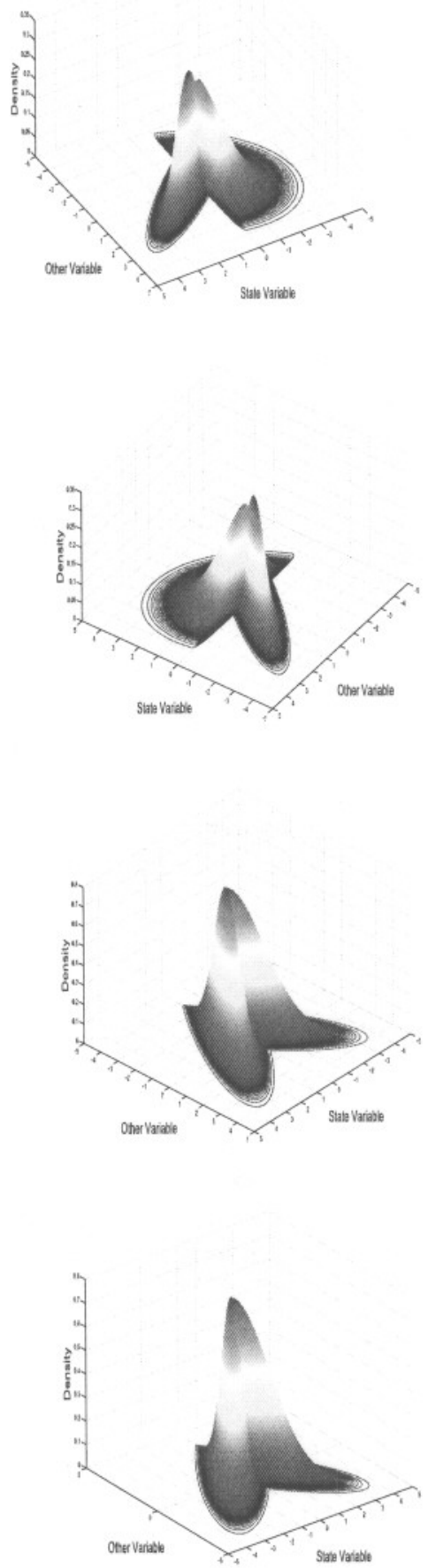

Contour Function
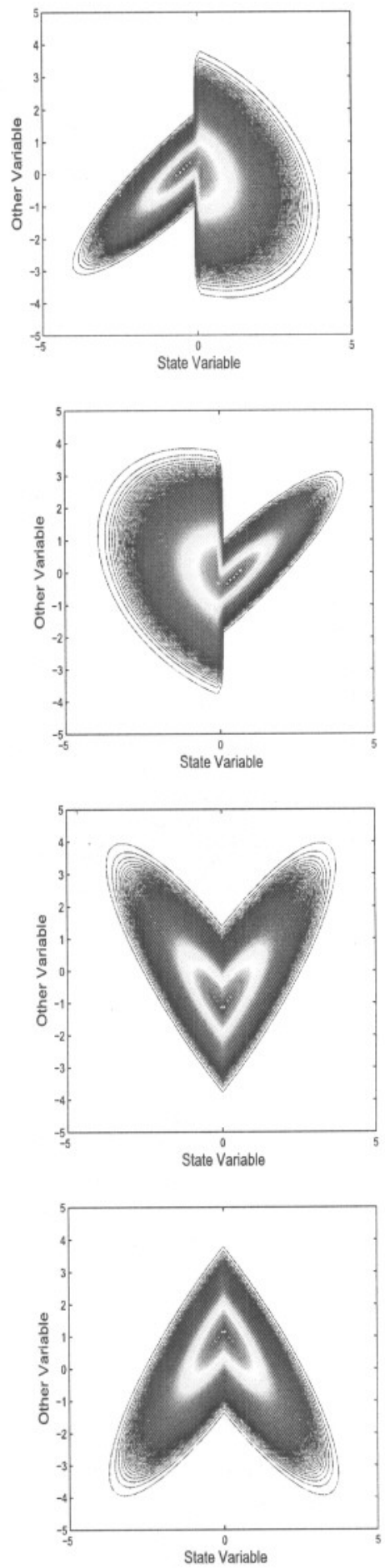
Figure 2. Equity Premia and State-Dependent Consumption Risks

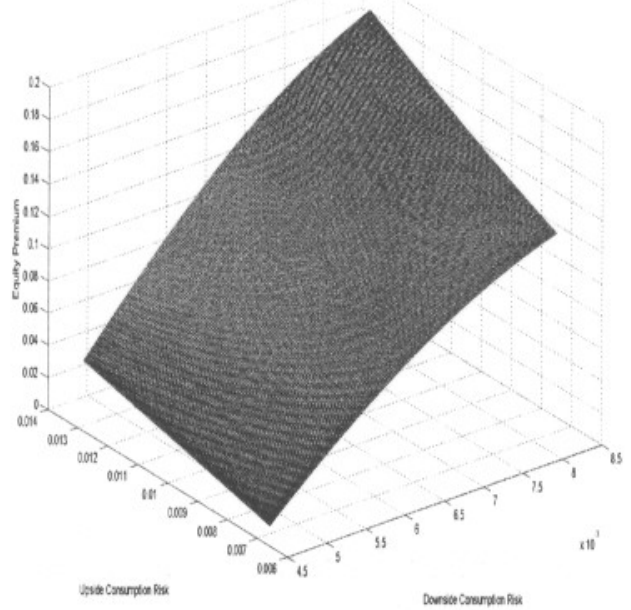


Figure 3. Equity Premia and State-Dependent Market Risks

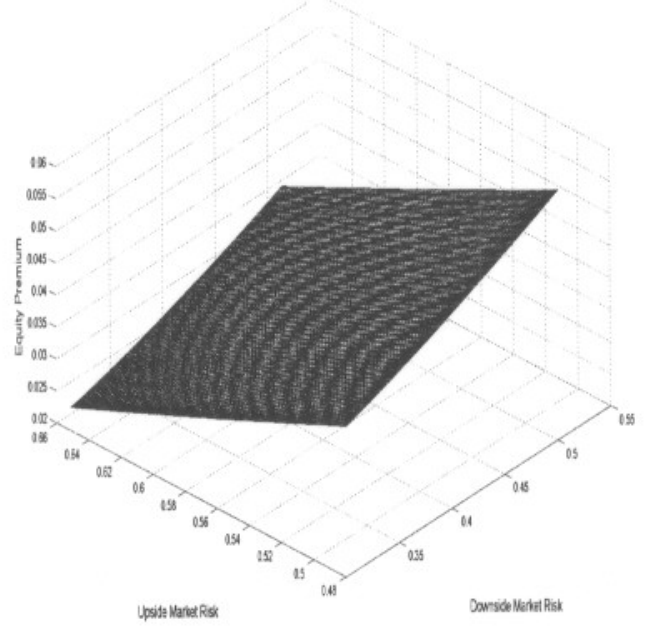


Figure 4. State-Dependent Risks and Responses
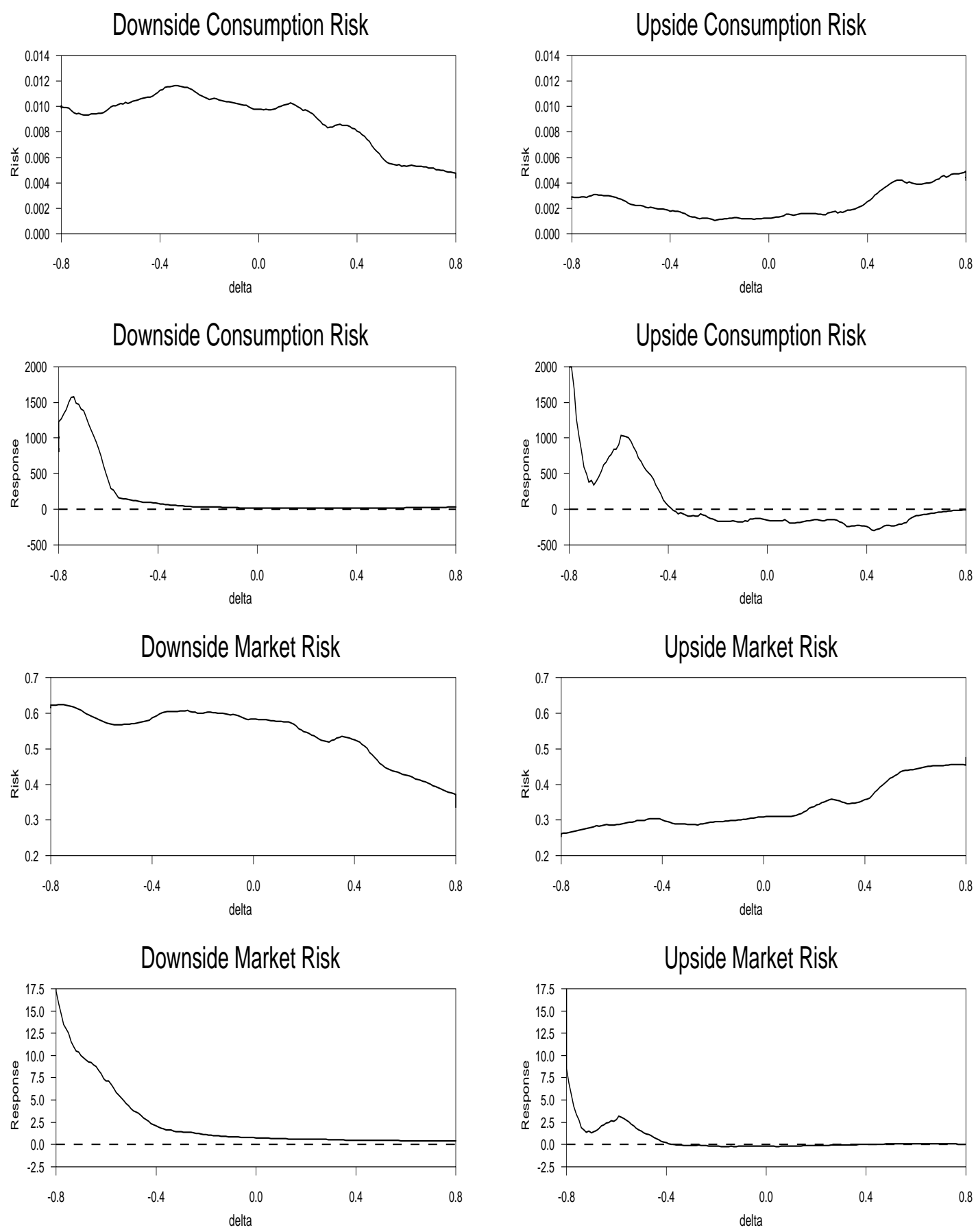

Note: Estimates of the state-dependent risks and responses for different values of the differential $\delta$. 